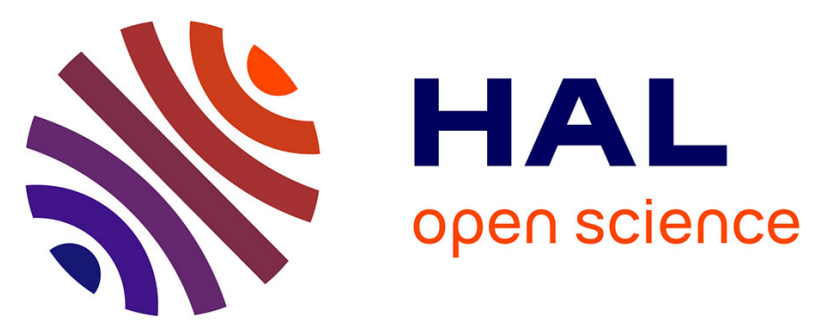

\title{
Bay of Bengal Sea surface salinity variability using a decade of improved SMOS re-processing
}

Valiya Parambil Akhil, Jérôme Vialard, Matthieu Lengaigne, Madhavan

Girijakumari Keerthi, Jacqueline Boutin, Jean-Luc Vergely, Fabrice Papa

\section{To cite this version:}

Valiya Parambil Akhil, Jérôme Vialard, Matthieu Lengaigne, Madhavan Girijakumari Keerthi, Jacqueline Boutin, et al.. Bay of Bengal Sea surface salinity variability using a decade of improved SMOS re-processing. Remote Sensing of Environment, 2020, 248, pp.111964. 10.1016/j.rse.2020.111964 . hal-03017400

\author{
HAL Id: hal-03017400 \\ https://hal.science/hal-03017400
}

Submitted on 21 Nov 2020

HAL is a multi-disciplinary open access archive for the deposit and dissemination of scientific research documents, whether they are published or not. The documents may come from teaching and research institutions in France or abroad, or from public or private research centers.
L'archive ouverte pluridisciplinaire HAL, est destinée au dépôt et à la diffusion de documents scientifiques de niveau recherche, publiés ou non, émanant des établissements d'enseignement et de recherche français ou étrangers, des laboratoires publics ou privés. 


\section{Highlights}

- The new debiased CATDS SMOS SSS product resolves major issues in the Bay of Bengal

- New SMOS has a comparable quality with SMAP and Aquarius, but over a full decade

- Confirms the post-monsoon southward transport of low saline water by the EICC

- Confirms that this transport is interannually modulated by the Indian Ocean Dipole 

improved SMOS re-processing

${ }^{4}$ ACRI-st, Guyancourt, France

${ }^{5}$ LEGOS, IRD/CNES/CNRS/UPS, Toulouse-France 


\section{Abstract}

Monsoon rain and rivers bring a large freshwater input to the Northern Bay of Bengal (BoB), yielding low Sea Surface Salinity (SSS) after the monsoon. The resulting sharp upper-ocean salinity stratification is thought to influence tropical cyclones intensity and biological productivity by inhibiting vertical mixing. Despite recent progresses, the density of in situ data is far from sufficient to monitor the BoB SSS variability, even at the seasonal timescale. The advent of satellite remotely-sensed SSS (SMOS, Aquarius, SMAP) offers a unique opportunity to provide synoptic maps of the BoB SSS every $\sim 8$ days. Previous SMOS SSS retrievals did not perform well in the BoB. Here, we show that improved systematic error corrections and quality control procedures yield a much better performance of the new "debiased v4" CATDS level-3 SSS from SMOS $(\sim 0.8$ correlation, 0.04 bias and 0.64 root-mean-square difference to more than 28000 collocated in situ data points over 2010-2019). The SMOS product now performs equivalently to Aquarius, and is slightly inferior to SMAP over the BoB. In particular, SMAP and SMOS are able to capture salinity variations close to the east coast of India ( $r>0.8$ within $75-150 \mathrm{~km}$ of the coast). They thus capture the seasonal freshening there, associated with equatorward advection of the Northern BoB low-salinity water by the East Indian Coastal Current (EICC) after the summer monsoon. The 10-year long SMOS record further allows to describe the BoB interannual SSS variability, which is strongest in boreal fall in relation with the Indian Ocean Dipole (IOD). Positive IOD events induce a weakening of the southward export of freshwater by the EICC, and hence negative SSS anomalies in the Northern BoB and positive ones along the East Indian coast. This confirms results from earlier studies based on modelling, sparse in situ data, or shorter satellite records, but this time from a 10-year long SSS record. Overall, our study indicates that the new SMOS retrieval can be confidently used to monitor the BoB 
SSS and to study its mechanisms. We end by a brief description of the BoB SSS anomalies associated with the extreme 2019 IOD event and highlight the very good performance over the $\mathrm{BoB}$ of a new multi-satellite product developed by the European Space Agency merging SMOS, Aquarius and SMAP data.

\section{Highlights}

- The new debiased CATDS SMOS SSS product resolves major issues in the Bay of Bengal

- New SMOS has a comparable quality with SMAP and Aquarius, but over a full decade

- Confirms the post-monsoon southward transport of low saline water by the EICC

- Confirms that this transport is interannually modulated by the Indian Ocean Dipole

Keywords: Bay of Bengal, Sea Surface Salinity, SMOS, SMAP, AQUARIUS, East Indian Coastal Current, Indian Ocean Dipole 


\section{Introduction}

The Bay of Bengal (hereafter, BoB) is one of the rainiest areas of the Asian summer monsoon region. As a result, this relatively small basin receives large freshwater inputs during and shortly after the summer monsoon, dominantly as rain in the northeastern basin, but also from two large rivers: the Ganga-Brahmaputra in the north and the Irrawaddy in the northeast (e.g. Akhil et al., 2014; Chaitanya et al., 2014; Papa et al., 2010; see Figure 1 for the location of these rivers). This basin is hence characterized by low surface salinity during and after the summer monsoon (e.g. Rao and Sivakumar, 2003), leading to a sharp upper-ocean salinity stratification (e.g. Shetye, 1993; Thadathil et al., 2016).

The stabilizing effect of this near-surface freshening is thought to have important climatic consequences by inhibiting vertical mixing. The haline stratification indeed reduces the vertical mixing of heat during and after the summer monsoon (e.g. de Boyer Montegut et al., 2007; Thadathil et al., 2016; Shenoi et al., 2002; Krishnamohan et al., 2018), although the overall influence on climatological sea surface temperature (and thus rainfall) may be weak due to compensating processes (Krishnamohan et al., 2018). The salinity stratification also inhibits vertical mixing below tropical cyclones (e.g. Neetu et al., 2012; Sengupta et al., 2008), thereby reducing the air-sea coupling negative feedback, and strengthening post-monsoon cyclones (Neetu et al., 2019). It is also believed to inhibit vertical mixing of nutrients and to reduce marine biological productivity in the BoB (Prasanna Kumar et al., 2002). For all those reasons, it is important to monitor Sea Surface Salinity (hereafter, SSS) variations in this basin.

The strong seasonality of the freshwater forcing yields strong SSS seasonal variations in the $\mathrm{BoB}$. The northeastern $\mathrm{BoB}$ indeed experiences an intense freshening 
right after the monsoon, attributable to the freshwater forcing from rivers and rain (e.g. Rao and Sivakumar, 2003; Akhil et al., 2014). This fresh pool expands southward in the following months as a narrow fresh tongue in a $\sim 100 \mathrm{~km}$ wide strip along the East Indian coast, a feature nicknamed "river in the sea" by Chaitanya et al. (2014). This river in the sea results from the southward export of the northeastern BoB freshening by the East Indian Coastal Current (hereafter, EICC), a narrow western boundary current that flows southward in boreal fall, before vertical mixing restores higher salinities during winter (Chaitanya et al., 2014; Akhil et al., 2014). The Indian Ocean Dipole (hereafter, IOD; Saji et al., 1999), an Indian Ocean interannual climate mode, modulates the "river in the sea" southward expansion, through its remote impact on the EICC (Akhil et al., 2016a; Fournier et al., 2017; Sherin et al., 2018). At smaller scales, oceanic eddies also induce meandering of the salinity front, exporting freshwater offshore (Benshila et al., 2014; Hareesh Kumar et al., 2013; Sengupta et al., 2016; Fournier et al., 2017).

The sparse in situ SSS data has for long prevented a detailed description of basin-scale BoB SSS variability, especially at the relatively fine spatial scales associated with the "river in the sea". Salinity climatologies built from historical in situ data compilation (e.g. Chatterjee et al., 2012; Antonov et al., 2010) provided a rough description of the BoB SSS seasonal cycle, but their limited data coverage resulted in an excessive smoothing of the SSS structure and particularly of coastally confined river in the sea (Chaitanya et al., 2014). While punctual near-shore cruises provided snapshots of this coastal freshening (Shetye et al., 1996) as well as its meandering induced by eddies (Hareesh Kumar et al., 2013), in situ observations are still not dense enough to allow a systematic and detailed description of the BoB SSS spatio-temporal variability despite recent improvements due to the Argo program. As an illustration, Figure 1a,b shows that available in situ observations are not able to capture the basin-scale seasonal mean SSS 
pattern associated with the 2015 positive IOD and the 2016 negative IOD, with a dearth of in situ data near the coastline where SSS signals are the strongest. The surface salinity measurements from recent satellite missions may help to improve this description but satellite monitoring of BoB SSS is complex, because of strong "Radio-Frequency Interferences" (RFI) in Asia (Oliva et al., 2016), and pollution of the signal over sea by nearby land signals (Anterrieu et al., 2015).

Three recent spaceborne missions may help improving the BoB SSS description. Measurements from the Soil Moisture and Ocean Salinity (SMOS) mission of the European Space Agency (ESA) launched in 2009 have a mean resolution close to $50 \mathrm{~km}$, theoretically sufficient to monitor small-scale structures such as the narrow "river in the sea". But unfortunately, because of the complex antennas geometry, the land contamination and radio frequency interference (RFI) extends up to $\sim 1000 \mathrm{~km}$ away from coast (Reul et al., 2013, Oliva et al 2016). The large antenna lobes make the land contamination very dependent on the orientation of the satellite track relative to the coast (Boutin et al., 2018). Until recently, this resulted in virtually useless SSS retrievals in the BoB (Boutin et al., 2013; Subrahmanyam et al., 2013; Akhil et al., 2016b). The land contamination mitigation is conceptually simpler for the two other spaceborne missions of the National Aeronautics and Space Administration (NASA), namely the Aquarius/Sac-D mission launched in 2011 and the Soil Moisture Active Passive (SMAP) mission launched in 2015 (Meissner et al., 2018; Fore et al., 2017). Given the resolution of its main antenna lobes, Aquarius however only provides SSS measurements at an effective resolution of $\sim 150 \mathrm{~km}$, which can only resolve the BoB large-scale SSS patterns but not the "river in the sea" (Akhil et al., 2016b). In addition, the Aquarius mission ended in 2015 due to an unrecoverable hardware failure. In contrast, SMAP provides SSS retrieval at a spatial resolution similar to that of SMOS, and suffers from lighter 
land contamination issues compared to SMOS (Reul et al., 2013). As a result, SMAP provides unprecedented views of small-scale BoB SSS features, including the influence of mesoscale eddies and of the IOD on the river in the sea (Fournier et al., 2017). As already demonstrated in Fournier et al. (2017), Figure 1c,d indeed illustrates that the river in the sea extends $\sim 800 \mathrm{~km}$ further south in fall 2016 (negative IOD) than in fall 2015 (positive IOD), hence providing the first observational confirmations of previous modelling results (Akhil et al., 2016a).

Monitoring the full spectrum of SSS variations in the BoB however requires longer time series than those currently provided by SMAP. A recent reprocessing of SMOS data with an improved correction of systematic errors and refined quality control procedures (Boutin et al., 2018) demonstrated that SMOS data could provide a data quality close to that of SMAP. This recent dataset may allow monitoring the BoB spatiotemporal SSS variations over a longer period ( $\sim 10$ years) than SMAP ( $\sim 5$ years). In the current paper, we analyse an updated version of this dataset to investigate whether the most recent SMOS reprocessing can provide accurate SSS retrievals in BoB, especially near the coast. SSS patterns derived from this new product in fall 2015 and 2016 are indeed very similar to those depicted by SMAP (Figure 1e-f), suggesting that it may be useful to complement SMAP data before 2015. Section 2 describes our methodology and datasets. Section 3 assesses how the Boutin et al. (2018) reprocessing improves the SMOS SSS retrieval in the BoB, based on a comparison to available in situ observations, to previous SMOS retrieval and to Aquarius and SMAP retrievals. Section 4 takes advantage of the 10-year long (2010 to 2019) SMOS record to describe BoB SSS seasonal cycle and interannual variability. Section 5 provides a summary and discussion. We also briefly discuss the very promising performance over the BoB of a new merged SMOS-Aquarius-SMAP data product developed by the European Space Agency (ESA). 


\section{Dataset and methods}

162

163

164

165

166

\subsection{SSS datasets}

We analyse SSS datasets derived from different satellites (SMOS, Aquarius and SMAP). The SMOS-old and Aquarius datasets are described in more details in Akhil et al. (2016b), and the SMAP dataset in Fournier et al. (2017). Their most salient characteristics are summarized below.

The SMAP platform was launched on 31 January 2015 and began operating from April 2015. We use the version-4.3 SMAP SSS, gridded Level-3 dataset, distributed by the "Jet Propulsion Laboratory (JPL)", at 8-days temporal and $0.25^{\circ}$ spatial resolution. This product is available from the $6^{\text {th }}$ April 2015 to near real time (Yueh et al., 2013, 2014) and is analysed up to $30^{\text {th }}$ December 2019 in the present paper. For Aquarius (Lagerloef et al., 2008), we analyse the Version-5, Level 3 gridded, SSS dataset, released by the NASA "Physical Oceanography Distributed Active Archive Center (PODAAC)", which provides 7 day running-means at $1^{\circ}$ resolution, between August 2011 and June 2015. The approximate effective resolution is $\sim 60 \mathrm{~km}$ for SMAP and $150 \mathrm{~km}$ for Aquarius. A description of the products version, data repository, temporal and spatial resolution and analysed period is provided in Table 1.

As mentioned in the introduction, we also analyse two versions of the SMOS data. The first one ("SMOS-old" in the following) is the dataset described in Akhil et al. (2016b); i.e. the version-2, Level-3 gridded SMOS SSS research product, produced by the "CATDS/Ifremer", at a horizontal resolution of $0.25^{\circ}$ for 10 -day running means. The second dataset ("SMOS-new" in the following) is the Level-3 gridded SMOS SSS 
'debiased' version-4 (Boutin et al., 2018) generated by the "LOCEAN/ACRI-ST Expertise Center", with resolution of $0.25^{\circ}$ for 9-day running means, from January 2010 to September 2019. The effective resolution of these two datasets is approximately 70km. SMOS-old SSS were de-biased using a crude method which did not take the geometry of the coast into account and excluded pixels that were too far away from the in situ climatology in $5^{\circ} \times 5^{\circ}$ pixels. SMOS-new uses an improved systematic error correction near land, and a less rigorous quality control of the radiometric measurements in regions where the SSS variability is large, as in Boutin et al. (2018). One of the main changes between the 'debiased' version-4 we use here and 'debiased' version-2 in Boutin et al. (2018) is an improved adjustment of the absolute SSS close to coast, by adjusting the upper quantile of the SMOS SSS to the ISAS in situ climatology (Gaillard et al., 2016) instead of the median (equation 4 of Boutin et al., 2018). This significantly improves the comparison of SMOS 'debiased' v4 to SMAP SSS, relative to the 'debiased' v2 (not shown).

\subsection{In situ salinity data}

The in situ dataset used to quantitatively validate these satellite products gathers all the BoB SSS measurements in the "World Ocean Database" (hereafter WOD; Boyer et al., 2018; Garcia et al., 2018) over the 2010 to 2019 period. The main contributors to this dataset are Argo profilers (“Array for Real-Time Geostrophic Oceanography”, Roemmich et al., 2009). This dataset also includes XCTD ("eXpendable ConductivityTemperature-Depth") profiles, moored buoys data, ocean drifters and glider data. As WOD gathers different data sources, the depth at which these measurements are retrieved varies from 1 to $5 \mathrm{~m}$. As discussed in Chaitanya et al. (2015) and Akhil et al. 
(2016b), the error arising from these diverse sampling depths is negligible relative to horizontal SSS variations within retrieved data grid cells in this region. This dataset includes more than 28000 valid measurements but its coverage is rather heterogeneous as indicated in Figure 2a, with a dense sampling in the central BoB but sparse data close to the coasts and in the Andaman Sea. These in situ data are binned into a $1^{\circ} \mathrm{x} 1^{\circ}$ monthly gridded dataset by taking the median of individual measurements in every bin. A similar gridding is performed for the various satellite datasets. We further define four $\mathrm{BoB}$ sub-regions that are outlined on Figure $2 \mathrm{~b}$. The NBoB ("Northern BoB", $86^{\circ} \mathrm{E}$ to $94^{\circ} \mathrm{E}$ and $16^{\circ} \mathrm{N}$ to $23^{\circ} \mathrm{N}$ ) exhibits the largest SSS variations. The WBoB ("western BoB", $80^{\circ} \mathrm{E}$ to $84^{\circ} \mathrm{E}$ and $6^{\circ} \mathrm{N}$ to $16^{\circ} \mathrm{N}$ ) encompasses the "river in the sea" during fall. The ANDA (“Andaman Sea", $94^{\circ} \mathrm{E}$ to $99^{\circ} \mathrm{E}$ and $6^{\circ} \mathrm{N}$ to $18^{\circ} \mathrm{N}$ ) also host a prominent variability. The $\mathrm{CBoB}\left(“ \mathrm{Central} \mathrm{BoB}\right.$ ", $84^{\circ} \mathrm{E}$ to $94^{\circ} \mathrm{E}$ and $6^{\circ} \mathrm{N}$ to $16^{\circ} \mathrm{N}$ ) is the region of weakest variability.

We also use the $15^{\circ} \mathrm{N}$ and $90^{\circ} \mathrm{E}$ RAMA ("Research Moored Array for AfricanAsian-Australian Monsoon Analysis and Prediction"; McPhaden et al., 2009) mooring salinity data at $5 \mathrm{~m}$-depth to validate the satellite at this location. The mooring does not provide 5m data after May 2018, so the validation of the satellite with RAMA is restricted to the January 2010 to May 2018 period. The newly updated climatology WOA18 (Zweng et al., 2018) with $0.25^{\circ} \mathrm{X} 0.25^{\circ}$ degree horizontal resolution is also used for qualitatively validating the satellite data salinity seasonal cycle in Figure 8.

\subsection{Ancillary datasets}

For Sea Level Anomalies (SLA), we use AVISO dataset ("www.aviso.oceanobs.com/fr/accueil/index.html"; Ducet et al., 2000), which merges data from different altimeters. The BoB surface circulation is obtained from the GEKCO 
(“Geostrophic and Ekman Current Observatory"; Sudre et al., 2013) surface current available from October 1992 to present. This product includes both surface geostrophic currents derived from altimetry and the Ekman flow derived from scatterometer winds. We use satellite-derived monthly estimates of Ganges-Brahmaputra river discharge at the river mouths (Papa et al., 2010), estimated from the joint use of in situ leveldischarge rating curves and altimetry-derived water level at the river mouth (Papa et al., 2012). This dataset is unfortunately available up to 2016 only.

In the following section, we will define several climate modes indices. Those indices are traditionally defined from Sea Surface Temperature (SST), for which we use NOAA

(https://www.esrl.noaa.gov/psd/data/gridded/data.noaa.oisst.v2.highres.html). But we will see that a SST-based index maybe not the best choice for the Indian Ocean Dipole (IOD), and will propose alternatives, in particular based on Outgoing Longwave Radiation (OLR, a proxy of deep atmospheric convection) or Wind Stress (the force exerted by wind per unit ocean surface). Wind stresses up to August 2019 are calculated from the ERA-Interim daily winds by using the bulk formula $\boldsymbol{\tau}=\boldsymbol{\rho} \mathbf{C}_{\mathbf{D}} \mathbf{U}^{*} \mid \mathbf{U I}$, where $\boldsymbol{\rho}$ the density of the air, $\mathbf{C}_{\mathbf{D}}$ the drag coefficient (here assumed to be $1.2 \times 10^{-3}$ ), and $\mathbf{U}$ the wind vector at 10-m height. We use the National Oceanic and Atmospheric Administration interpolated

OLR data (https://www.esrl.noaa.gov/psd/data/gridded/data.interp_OLR.html).

\subsection{Climate indices}

We will relate interannual SSS variations in the BoB to well-known modes of climate variability. The Indian Ocean Dipole (Saji et al., 1999) peaks in boreal fall (typically September-November). In its positive phase, the IOD is characterized by cold 
SST anomaly along the coast of Java and Sumatra and warm SST anomaly over the western Indian Ocean (Fig. 3b). Because of this SST anomaly pattern, a classical index proposed to characterize the IOD is the Dipole Mode Index (hereafter DMI; Saji et al., 1999), defined as the September-November (SON) average difference between SST anomalies in the western $\left(50^{\circ}\right.$ to $70^{\circ} \mathrm{E}$ and $10^{\circ} \mathrm{N}$ to $\left.10^{\circ} \mathrm{S}\right)$ and eastern $\left(90^{\circ}\right.$ to $110^{\circ} \mathrm{E}$ and $10^{\circ} \mathrm{S}$ to $0^{\circ}$ ) equatorial Indian Ocean.

It has been argued before that the DMI not only tracks dynamical perturbations associated with the IOD, but also more high frequency SST anomalies driven by synoptic atmospheric variability (e.g. Dommenget and Jansen, 2009), and that some other indices may be more accurate to represent the ocean-atmosphere coupling that characterizes the IOD (e.g. Shaaban and Roundy, 2017). Positive IOD events are for instance also characterized by reduced atmospheric convection in the eastern Indian Ocean, as evidenced by the positive OLR anomalies in this region (Fig. 3b). It has hence been suggested that an OLR based index could better distinguish IOD events than the classical SST-based DMI index (Shaaban and Roundy, 2017). We have thus defined an OLR-based Dipole Index (hereafter, ODI) inspired from that of Shaaban and Roundy (2017), but simply defined as average SON OLR interannual anomalies in the western $\left(50^{\circ}\right.$ to $70^{\circ} \mathrm{E}$ and $10^{\circ} \mathrm{N}$ to $\left.10^{\circ} \mathrm{S}\right)$ equatorial Indian Ocean minus those in the eastern $\left(90^{\circ}\right.$ to $110^{\circ} \mathrm{E}$ and $10^{\circ} \mathrm{S}$ to $0^{\circ}$ ) equatorial Indian Ocean. Those are the same boxes as those used for the DMI, and their choice is justified by the statistically significant OLR signals there (Fig. 3b).

Positive phase of IOD are also associated with easterly wind stress anomalies over the eastern Equatorial Indian Ocean (Fig. 3a). We have thus defined a Wind stressbased Dipole Index (WDI) as the average SON zonal wind stress anomaly over the 
eastern equatorial Indian Ocean (EEIO, $5^{\circ} \mathrm{N}-5^{\circ} \mathrm{S} ; 75^{\circ} \mathrm{E}-100^{\circ} \mathrm{E}$ ). Those wind stress anomalies induce a clear basin-scale Sea Level Anomalies (SLA) response (e.g. Webster et al. 1999; Suresh et al. 2018), with downwelling (i.e. positive SLA) along the south central Indian Ocean (Fig. 3a) in boreal fall (Webster et al. 1999; Keerthi et al., 2013) and upwelling (i.e. negative SLA) along the java Sumatra coast. We hence also defined a SLA-based Dipole Index (SDI) as the average SON SLA in the south central Indian Ocean SCIO, $5^{\circ} \mathrm{S}-15^{\circ} \mathrm{S} ; 65^{\circ} \mathrm{E}-90^{\circ} \mathrm{E}$ ) minus that near the Java/Sumatra coast (JSC; $0^{\circ}$ $\left.10^{\circ} \mathrm{S} ; 95^{\circ} \mathrm{E}-105^{\circ} \mathrm{E}\right)$.

The time evolution of the four IOD indices (the classical DMI and our SDI, WDI, and ODI indices) over the 1993-2018 period is displayed on Figure 3c. While all these indices share a lot in common, the DMI index departs from all the other indices in both 2017 and 2018, two years within our 2010-2018 study period. Statistics in Table 2 indicate that the DMI is the least consistent with the other indices (Table 2), with correlations ranging from 0.83 with the ODI to 0.89 with the SDI. In contrast, the SDI is strongly correlated with the WDI (correlation 0.97 ) a to a slightly lesser extend with the ODI. I.e. the IOD ocean-atmosphere signals seem to be better characterized by its SLA, OLR (atmospheric convection) and wind stress signals than by the DMI. This is not only true over the entire 1993-2018 period, but even more over our 2010-2018 study period (number in brackets in Table 2). In the text, we will thus use the SDI to characterize the IOD, and find that SSS interannual anomalies are more correlated with the SDI than with the DMI. We will not mention correlations with the ODI and WDI for the sake of brevity, but these two last indices also yield higher correlations with the IOD signals that we will discuss. In short, the SDI, ODI or WDI are better indices of the IOD than the DMI. 

averaged over central equatorial Pacific $\left(170^{\circ} \mathrm{W}-120^{\circ} \mathrm{W} ; 5^{\circ} \mathrm{N}-5^{\circ} \mathrm{S}\right)$ from November to

\section{Validation}

In this section, we evaluate SMOS-new SSS dataset in terms of spatial coverage and agreement with in situ observations. We first illustrate the much better performance of SMOS-new against SMOS-old dataset (section 3.1), and then focus on SMOS-new and compare its performance to that of the Aquarius and SMAP datasets (section 3.2).

\subsection{SMOS-new vs. SMOS-old}

Figure 2 displays the percentage of $1^{\circ} \times 1^{\circ}$ monthly values that can be retrieved from in situ, SMOS-old, SMOS-new, Aquarius and SMAP data. As discussed in Akhil et al. (2016b), many pixels of the SMOS-old product are flagged as bad values (Fig. 2c), in particular over the northern BoB. As a result, SMOS-old only achieves a nearly complete coverage south of $15^{\circ} \mathrm{N}$, with a northward decrease of the data coverage down to $<10 \%$ close to the Ganges-Brahmaputra estuary. In contrast, the SMOS-new product achieves a complete coverage over the entire domain (Fig. 2d). This coverage is far better than the one achieved from in situ data (Fig. 2b,d). In situ data typically achieves a $\sim 20 \%$ coverage in central $\mathrm{BoB}$, but does neither sample coastal regions nor the Andaman Sea. SMOS-new has thus a superior coverage to SMOS-old and very superior coverage to in situ data. 
Figure 4 compares SMOS-new and SMOS-old observations against in situ data.

The statistics for this comparison are provided for the entire datasets, but also between brackets for common data between SMOS-old, SMOS-new and in situ data, to allow a fair comparison. Both sets of statistics in fact indicate a clear improvement of SMOSnew relatively to SMOS-old, with an increase in correlation $(\sim 0.8$ vs. 0.6$)$ as well as a reduction of the bias ( $\sim 0.1$ vs. -0.14$)$ and root mean square difference (rmsd; $\sim 0.6$ vs. 0.95). This clear improvement remains valid when comparing both datasets separately for the four regions displayed in Figure $2 b$ (not shown). As shown in Figure 4, this improvement is partly due to the tendency of SMOS-old to overestimate low SSS (in the 25-32 pss range) and to underestimate high SSS (above 34 pss), which largely disappears in SMOS-new.

This broad analysis demonstrates the clear improvement of SMOS-new relative to SMOS-old and we will focus in the following on a more thorough evaluation of SMOS-new, in comparison with SMAP and Aquarius.

\subsection{SMOS-new vs. Aquarius and SMAP}

Figures 2d,e,f allow comparing the spatial coverage of SMOS-new, Aquarius and SMAP. The three products achieve a full coverage in most of the BoB, and only differ through their spatial resolution and coverage close to coasts. SMAP intermittently provides a couple of additional values close to coasts relative to SMOS-new. Both products are clearly superior to Aquarius in terms of data coverage, due to the lower resolution of Aquarius and some missing values in grid-points in the vicinity of coasts.

Figure 5 further provides statistics for comparisons between satellite products and co-located in situ data over their common periods (August 2011 to June 2015 for SMOS-New vs. Aquarius on Figure 5a; April 2015 to October 2019 for SMOS-new vs. 
SMAP on Figure 5b), i.e. these statistics are strictly comparable as they compare the satellites to identical common in situ samples. SMOS-new and Aquarius have an almost identical performance $(\mathrm{r} \sim 0.8, \mathrm{rmsd} \sim 0.65$ and bias $\sim 0.15)$. One may however argue that this is not a fair comparison, since SMOS SSS has a higher spatial resolution $\left(0.25^{\circ}\right.$ for the new SMOS product) than Aquarius $\left(1^{\circ}\right)$. We have hence re-gridded SMOS to the Aquarius $1^{\circ}$ grid through spatial averaging. The resulting $1^{\circ} \mathrm{SMOS}-\mathrm{new}$ has an almost identical fit to observations compared to SMOS-new on its native grid. This is a bit surprising, because there are a lot of fine-scale $\left(<1^{\circ}\right)$ salinity structures in the BoB (e.g. Wijesekera et al., 2016), and one would thus expect finer-resolution product to capture them better, and yield less representativity errors. The almost equivalent performance of SMOS-new product at these two resolutions could either arise from the fact that the SMOS-new product effective resolution is about $70 \mathrm{~km}$ in the BoB, or that SMOS has grid-point, unphysical noise, and whatever is gained in term of representativity is lost due to this noise. SMAP behaves slightly better than SMOS-new in the BoB (Fig. 5b), with slightly higher correlation $(0.85$ vs. 0.81$)$ and lower rmsd (0.59 vs. 0.65$)$. It does, however, have a slightly larger bias (0.08 vs. 0.11$)$.

Figure 5 evaluated the three remotely sensed SSS over the entire BoB. This validation has also been performed separately for the $\mathrm{NBoB}, \mathrm{WBoB}, \mathrm{CBoB}$ and $\mathrm{ANDA}$ regions (not shown), resulting in a similar conclusion: statistics of comparison with in situ SSS are generally equivalent with Aquarius and SMOS-new, and slightly better with SMAP than both products. Aquarius however performs slightly better than SMOS-new in the central $\mathrm{BoB}$ but this is compensated by a better SMOS-new performance in the Northern $\mathrm{BoB}$ and Andaman regions. Figure 6 provides an alternative regional validation of the SMOS-new dataset, by plotting box-averaged time series of in situ and SMOS-new SSS, both for co-located data at in situ points (continuous lines) and for the 
box-average SMOS-new data (dashed line), for the $\mathrm{NBoB}, \mathrm{WBoB}, \mathrm{CBoB}$ and ANDA regions. Figure 6 first clearly demonstrates that the in situ data sampling is clearly not sufficient for estimating the box-averaged SSS (compare the red dashed and continuous lines), especially in the $\mathrm{NBoB}$ and ANDA boxes. This figure also indicates an outstanding phase agreement between SMOS-new and in situ collocated data, with correlations exceeding 0.8 in all boxes other than $\mathrm{CBoB}$. The correlation is weakest for the $\mathrm{CBoB}$ region $(0.75)$, where the SSS variability is the weakest, hence yielding an unfavourable signal to noise ratio.

Since the central BoB seems to be a region where SMOS-new performs slightly worse than elsewhere in the BoB (Fig. 6), we provide a comparison of SMOS-new, SMAP and Aquarius with monthly-averaged salinity at $5 \mathrm{~m}$ depth from the $15^{\circ} \mathrm{N}$ and $90^{\circ} \mathrm{E}$ RAMA mooring in Figure 7. This comparison confirms that SMOS-new has a degraded performance relative to SMAP and Aquarius in the central BoB, with lower correlations and higher rmsd to in situ data (both over the entire period or when compared based on the same observational sample). Despite this degraded performance compared to other products, SMOS-new still captures SSS variability in the central BoB relatively well, with a 0.79 correlation and 0.40 pss rmsd over the entire period (January 2010- May 2018). Even if SMOS-new performs less accurately in the central BoB, it is still perfectly capable of detecting interannual anomalies such as the $\sim 2$ pss freshening events in 2012, 2013, 2014 and 2017 (Fig. 7).

Another traditionally difficult region for satellite products to accurately retrieve SSS is the coastal region of $\mathrm{WBoB}$, due to more prevalent RFI (Oliva et al., 2016) and contamination by signals from land (land brightness temperatures being typically about twice larger as those over the sea). This is particularly unfortunate along the East Indian 
coast, where the "river in the sea" is associated with strong seasonal and interannual SSS signals (Chaitanya et al., 2014; Akhil et al., 2014; Akhil et al., 2016a). In order to infer whether satellite data can be trusted in this region, Figure 8 provides the correlation between the three satellite products and co-located data points and the standard deviation of their difference (STDD), as a function of the distance to the east coast of India (within $\left.10^{\circ} \mathrm{N}-20.5^{\circ} \mathrm{N}, 78^{\circ} \mathrm{E}-90^{\circ} \mathrm{E}\right)$. In all products, the correlation drops close to the coast. This drop only occurs very close to the coast in SMAP (from $\mathrm{r} \sim 0.9$ at $100 \mathrm{~km}$ to 0.85 at $50 \mathrm{~km}$ ), which is a clearly superior product along the east coast of India. The decrease at the coast is however weaker for SMOS-new (from $\mathrm{r} \sim 0.8$ at $200 \mathrm{~km}$ to $\mathrm{r} \sim 0.75$ at $50 \mathrm{~km}$ off the coast) than for Aquarius ( $r \sim 0.83$ at $350 \mathrm{~km}$ to $\mathrm{r} \sim 0.65$ at $150 \mathrm{~km}$ ). Comparing the amplitude of the unbiased error (estimated as the standard deviation of the difference between the product and in situ data) with the amplitude of SSS variations for each product (estimated from the product and in situ data standard deviation) further allows evaluating if the accuracy of the measurements is smaller than the signal, i.e. if the signal to noise ratio is favourable. This is not so much the case for Aquarius, for which the STDD is $\sim 80 \%$ of the amplitude of the variability at $150 \mathrm{~km}$ away from the coast. SMOS-new and SMAP both allow to retrieve data closer to the coast, and to clearly monitor the increase in variability due to the "river in the sea" in the last $200 \mathrm{~km}$ from the coast. While the STDD increases close to the coast in both products, this typical error remains smaller than the signal to be measured, with a signal twice larger than the noise for SMAP. This result thus indicates that SMOS-new and SMAP are both able to capture the coastal SSS variations associated with the "river in the sea", with a better performance for SMAP. However, Figure 8a-c also indicates that the typical error becomes closer to the STD away from the coast (at $500 \mathrm{~km}$ ), illustrating that the lower SMOS-new performance in the central BoB (Fig. 6c) is indeed partly due to weaker 
signal-to-noise ratio there, as suggested above.

\section{Bay of Bengal SSS variability from a decade of SMOS data}

In the previous section, we have established the capability of SMOS-new, SMAP and Aquarius datasets to map large-scale variability of SSS in the BoB, including the regions close to the East Indian coast for SMOS and SMAP. In this section, we will describe the ability of these datasets to describe the BoB SSS seasonal cycle and interannual variability. We will then take advantage of the 10 years of SMOS data to describe BoB seasonal cycle. As SMOS-new record only extends up to September 2019 and the dominant modes of interannual variability peaks during and after September, the analysis of interannual SSS variability is restricted to 9 years (January 2010 to December 2018). We will however describe the SSS variability associated with an unusually strong IOD event in 2019 using August-December 2019 SMAP data (and show that it is consistent with SMOS-new data over August and September 2019).

\subsection{Seasonal cycle}

Figure 9 displays seasonal SSS maps constructed from the WOA18, SMOS-new, SMAP and Aquarius products, over the full period over which each product is available. While the SMAP (4-5 years) and Aquarius (3-4 years) records are too short to provide a precise estimate of the seasonal cycle, we underline that we only intend a qualitative comparison of the three satellites seasonal cycle with that from WOA18 (we already performed a quantitative comparison to in situ data in section 3). The newly available 25 km-resolution WOA18 has finer structures than previous versions, which were excessively smooth (Akhil et al. 2014). It captures meridional SSS variations, with lowest SSS in the Northern BoB in SON (i.e. after the large rainfall and river runoff peak towards the end of the Southwest monsoon, e.g. Chaitanya et al., 2014). WOA18 
also captures better fine-scale features such as the sharp SSS gradients at the river mouths and the post-monsoon "river in the sea" along the Western BoB, although this freshwater tongue hugging the East Indian coast is discontinuous in this dataset (Fig. 9c). The three satellite datasets reveal a similar seasonal salinity pattern, with low salinity (below 30 pss) close to the Ganges-Brahmaputra and Irrawaddy river mouths from June to February, but SMOS and Aquarius fail to capture the SSS signature of those two rivers during the dry season (MAM). The "river in the sea", associated with equatorward advection of the low salinity water in the Northern BoB by the southward post-monsoon EICC (Akhil et al., 2014; Chaitanya et al., 2014) is clearest in SMOS-new (Fig. 10a) and SMAP during boreal fall, where its freshening signature can be tracked as far south as the east coast of Sri Lanka. In contrast, Aquarius and WOA18 display a less coastally-trapped and more discontinuous freshening along the East Indian coast that does not reach the Sri Lankan east coast. Overall, SMOS-new and SMAP thus tend to display finer-scale structures than the other datasets.

Figure 10b further displays a SSS (contours) and along-shore currents (colors, with blue/negative indicating southward currents) latitude-time section, averaged within $200 \mathrm{~km}$ of the East Indian coast (red box in Fig. 10a). This Figure is comparable to Figure 6 in Akhil et al. (2014) modelling study or Figure 8 of Chaitanya et al. (2014) observational study and displays very similar features. The Northern BoB starts freshening in June onward during the monsoon onset, reaches its lowest climatological SSS in September, and goes back to pre-monsoon values by January-February. The southward expansion of this low salinity water along the East Indian coast coincides with the development of the southward EICC in October, while the return to premonsoon values starts occurring before the EICC turns northward (Fig. 10b), as pointed out by Akhil et al. (2014) and Chaitanya et al. (2014). Through a detailed upper ocean 
salinity budget, these last studies demonstrated that advection is the main cause for the "river in the sea" southward expansion, while vertical mixing strongly contributes to restoring the coastal SSS to pre-monsoon values. The 10-year long SMOS-new dataset yields salinity variations that are consistent with those conclusions.

\subsection{Interannual variability}

The insufficient in situ data coverage (Fig. 2a,b) only allows a rough description of the observed BoB SSS interannual variations. Based on gridded in situ data products, Pant et al. (2015) and Chaitanya et al. (2015) both reported strong interannual SSS variations in the western BoB. The observational study of Pant et al. (2015) and the modelling results of Akhil et al. (2016a) indicate that the IOD plays a prominent role in driving interannual SSS variability in boreal fall, in the northern and western BoB. Both studies indicate that the IOD remotely drives current anomalies through the coastal Kelvin waves propagation, which modulates the EICC intensity. The remote control of the IOD on the EICC is confirmed by the observational \& modelling study of Sherin et al. (2018), which however does not discuss the resulting SSS anomalies. Here, we take advantage of the 9 year-long SMOS-new dataset to investigate if satellite SSS data yields a consistent description to that in those studies.

Figure 11 confirms that largest year-to-year SSS variations in the northern and western BoB occur during September-November in the SMOS-new data, in agreement with Akhil et al. (2016a) modelling study. We have hence performed an "Empirical Orthogonal Function" (hereafter, EOF) analysis on the September to November (SON) average SSS anomalies (Fig. 12). We focus on the first EOF as it represents $43.2 \%$ of the total SSS anomalies variance, compared to less than $20 \%$ for higher modes. It is associated with opposite polarity SSS anomalies in the northern and western BoB (Fig. 
12b). Its principal component (PC1) has a 0.65 to 0.84 correlation with the four different IOD indices described in the method section (significantly different from zero above the $95 \%$ confidence level when considering each year as an independent sample). The correlation with ENSO is much weaker $(\mathrm{r}=0.07)$, and not statistically significant. This confirms that the leading mode of SSS anomalies in the BoB is strongly related to the IOD variability, with positive IOD events generally leading to negative SSS anomalies in the northern $\mathrm{BoB}$ and positive SSS anomalies along the west coast of $\mathrm{BoB}$, in agreement with Akhil et al. (2016a) modelling study and Pant et al. (2015) in situ data analysis. The correlation with PC1 is largest when considering the SDI (SLA-based IOD index, $\mathrm{r} \sim 0.84)$. This indicates a tight relation between the BoB SSS interannual anomalies and the SLA (and hence circulation) anomalies associated with the IOD, consistently with the results of Pant et al. (2015) and Akhil et al. (2016a). Because of this tight link, and because the DMI erroneously points to IOD events to 2017 and 2018 (Fig. 3c), we will hereafter mostly use the SDI as our best indicator of the IOD circulation anomalies.

Red arrows on Figure 12b display the GEKCO surface current anomalies obtained through a linear regression on PC1 time series. They indicate northward current anomalies along the East Indian coast, i.e. EICC weakening. The associated SLA signal (Fig. 12c) confirms that the EICC weakens during positive IOD events, in association with upwelling coastal Kelvin waves emanating from the equatorial region, as suggested by previous studies (Aparna et al., 2012, Akhil et al., 2016a, Suresh et al. 2018; Sherin et al., 2018). The EICC normally exports Northern BoB fresh water southward along the East Indian coast (Fig. 10a). Positive IODs weaken the EICC, hence resulting in a weaker southward fresh water export along the East Indian coast, qualitatively consistent with the typical negative anomalies in the northern BoB and positive anomalies in the 
western BoB (Fig. 12b). This is qualitatively consistent with the role of advection.

Figures 13 and 14 further allow detailing the year-to-year SSS variations along the East Indian coast over the 2010-2018 period and their main drivers. Figure 13 shows the SDI, and the SSS and along-shore currents latitude-time section along the Indian coast (red box in Fig. 10a). This period encompasses two positive IOD years (2011 and 2015) and two negative IOD years (2010, 2016; Fig. 13a). The EOF analysis in Figure 12ab and the case study of Fournier et al. (2017) indicate that the "river in the sea" tends to be less (more) developed during positive (negative) IOD years. This is confirmed by Figure 13bc: no clear "river in the sea" and positive SSS anomalies along the East Indian coast are depicted in 2011 and 2015, while a clearer "river in the sea" and negative SSS anomalies are seen in 2010 and 2016. The 2016 negative SSS anomalies are weak, however, and there are other years (such as 2013) that can also yield negative SSS anomalies along the East Indian coast. This indicates that the IOD is not the sole controller of year-to-year SSS variations along the East Indian coast, and we will come back to this point in the discussion.

Let us now examine the year-to-year variations of SSS in the two regions with the strongest SSS variability (East Indian coast and northern BoB) in more details. Figure 14 displays time series of Northern BoB Ganges-Brahmaputra runoff anomalies, SSS anomalies in the northern and western BoB as well as along-shore current anomalies along the East Indian coast over the 2010-2018 period. The dashed line shows the part of the interannual anomalies that are attributable to the IOD (obtained as the part that is linearly related to the IOD, through regression on the SDI). In general, the interannual variability of the northern BoB freshwater fluxes is quite independent from that of the IOD over the period we consider $(r \sim-0.4$ between Ganges-Brahmaputra runoff 
and SDI). There is, however, a stronger control of the Northern $(\mathrm{r} \sim-0.7)$ and southwestern BoB SSS ( $r \sim 0.8)$ and along-shore current ( $r \sim 0.7)$ anomalies by the IOD, as discussed earlier.

For instance, the northern BoB exhibits the strongest anomalous saltening in 2010 and 2016 (plain lines in Fig. 14b) in agreement with typical negative IOD years (compare the dashed and plain lines for these two years in Fig. 14b). The northern BoB freshens during the 2011 and 2015 positive IOD years, but more than would normally be expected in 2011. The anomalous saltening along the East Indian coast is strongest in 2011 and 2015, consistent with a positive IOD those two years (Fig. 14d). The anomalous freshening along the East Indian coast is however weaker than expected in 2016 (e.g. weaker than in 2012, a neutral IOD year). This underlines again that, with only $40 \%$ of the variance explained at the basin scale, the IOD is not the sole phenomenon that controls the interannual SSS variability in the BoB. Snapshots of the SSS (not shown) for instance suggest that a mesoscale eddy resulted in exporting a lot of freshwater from the "river in the sea" to the basin interior in 2016, hence diverting the fresh water from its along-shore southward path, and resulting in the relatively weak SSS anomalies for a negative IOD year in 2016.

Finally, some years with no IOD event can be associated with non-negligible SSS anomalies in the BoB. Let us focus on year 2012, which exhibits a positive but modest IOD index value. This year is associated with anomalously fresh SSS anomalies in the northern $\mathrm{BoB}$, larger than what expected from the IOD index value that year (Fig. 14a). This behaviour may be attributable to anomalously strong Ganges-Brahmaputra runoff in 2012 (Fig. 14a,b). This is coherent with Akhil et al. (2016a) modelling results that indicate that the second EOF of BoB SSS variability during boreal fall is associated 
with northern BoB SSS variations in response with the Ganges-Brahmaputra interannual anomalies. We will discuss this further in section 5.2. A strong anomalous freshening in the northern BoB is also observed in 2017, a year with a very weak IOD index value. The unavailability of Ganges-Brahmaputra runoffs data after 2016 however prevents assessing the role of freshwater forcing on this anomalous event.

\subsection{The 2019 positive IOD}

The availability of SMOS data until September 2019 and of SMAP data up to present gives us the opportunity to describe the anomalous SSS pattern in the BoB related to the extreme positive IOD event in fall 2019 (Doi et al., 2020). We used the common SMOS and SMAP period to compute interannual anomalies, and the common August and September 2019 months indeed confirm that SMOS and SMAP are quite consistent over these two months. We will thus focus on SMAP to describe SSS anomalies associated with the strong 2019 IOD.

The circulation and SSS anomalies in October-November 2019 are qualitatively consistent with those deduced from the Figure 12 EOF analysis, with a weaker than usual EICC associated with salty anomalies along the southern portion of coast of India, and fresh anomalies in the Northern BoB. The salty anomaly along the entire coast of India, associated with an unusually weak EICC had actually already started in August and September, when the fresh anomaly was more confined to the vicinity of the Ganges-Brahmaputra river mouth. While those anomalies are roughly consistent with those of the EOF analysis, they are very large, possibly due to the very large IOD amplitude in 2019 (Doi et al., 2020). There is also a very strong modulation of the salinity field by mesoscale activity, as noted previously by Fournier et al. (2017). Finally, the case of 2019 suggests that the EOF analysis pattern develops in two stages, 
first with positive SSS anomalies along the coast of India, and then with negative anomalies in the Northern BoB. The exact timing of this development and strong modulation by the mesoscale field suggest that more years will be needed in order to obtain a robust estimate of the dominant pattern of IOD-induced SSS variability in the BoB from remotely sensed data. This is further discussed in section 5.

\section{Summary and Discussion}

\subsection{Summary}

Past studies have underlined that the BoB SSS distribution can influence the intensity of tropical cyclones and the marine productivity by acting as a barrier to the upward mixing of colder water and nutrients into the surface mixed layer (Prasanna Kumar et al., 2002; Neetu et al., 2019). This is a strong motivation for a reliable monitoring of the year-to-year SSS variations in the BoB. In this paper, we show that currently available in situ data are not sufficiently dense to allow a proper mapping of the fine SSS structure in the BoB, even at seasonal timescale. In contrast, the SMOS, Aquarius, and SMAP satellite missions can provide synoptic maps of the basin SSS every $\sim 8$ days with a resolution of $\sim 50-100 \mathrm{~km}$. The first attempts to estimate BoB SSS from SMOS were unsuccessful (Boutin et al., 2013; Subrahmanyam et al., 2013; Akhil et al., 2016b), because of a suboptimal processing of systematic errors and too stringent quality control in that dataset. The new processing of Boutin et al. (2018) introduces an improved systematic-error correction and better accounts for the amplitude of the SSS signal during the quality control. Over the $\mathrm{BoB}$, this results in a $100 \%$ spatial coverage for $1 / 4^{\circ}$ SSS maps every 4 days over the 2010-2019 period that capture the basin-scale SSS variability well ( 0.81 correlation, 0.10 bias and 0.65 rms-difference relative to more 
than 26000 collocated 1-4 m depth in situ data over the basin). Comparison with SMAP and Aquarius data further indicate that the new SMOS processing has a similar performance to Aquarius (but better spatial resolution) and slightly inferior performance to SMAP over the BoB. The new SMOS processing has a degraded performance in the central $\mathrm{BoB}$ but still compares well with RAMA mooring data at $15^{\circ} \mathrm{N}-90^{\circ} \mathrm{E}(0.79$ correlation, 0.00 bias and $0.37 \mathrm{rms}$-difference). Despite errors that increase toward the coast of India, SMOS and SMAP still retain a favourable signal-to-noise ratio, and high correlations with available in situ observation datas close to the coast ( $\mathrm{r} \sim 0.74$ for SMOS and 0.83 for SMAP $75 \mathrm{~km}$ away from the coast).

The advantage of the SMOS new processing relative to SMAP and Aquarius is the length of its record ( $\sim 10$ years), that allows examining the BoB SSS seasonal cycle and interannual variability and to compare it with previous studies, based on either modelling or sparse in situ data. The new SMOS processing confirms that the largest seasonal signals are related to a northern $\mathrm{BoB}$ freshening during and shortly after the southwest monsoon, and its southward expansion along the west coast of India in fall, due to advection by the EICC. The strongest interannual variability occurs during September-November, in association with the IOD. Remote forcing associated with the IOD modulates the EICC intensity through coastal Kelvin waves radiating from the equatorial strip to the western BoB. The EICC is anomalously weak during positive IOD events, resulting in less southward freshwater export, and hence negative SSS anomalies to the north of the $\mathrm{BoB}$ and positive SSS anomalies along the East Indian coast. Opposite anomalies occur during negative IOD events. These anomalies are however modulated by other processes than the IOD. For instance, Ganges-Brahmaputra River discharge variations seem to also contribute to northern BoB SSS anomalies during some years. Similarly, eddies induce strong offshore transport, and thus modulate SSS 
along the East Indian coast.

\subsection{Discussion}

Let us first compare the results of the present study with previous analyses. Previous studies of the BoB SSS either relied on modelling or on sparse in situ data that do not resolve the strong salinity gradients. First, the present study confirms large SSS seasonal signals in the northern BoB during and after the monsoon (e.g. Akhil et al., 2014; Rao and Sivakumar, 2003). Most importantly, it confirms that a fresh salinity tongue associated with steep salinity gradients develop along the East Indian coast after the summer monsoon, in agreement with sparse observations from cruises (e.g. Shetye et al., 1993; Hareesh Kumar et al., 2013), modelling results (Jensen, 2001; Akhil et al., 2014), observations collected directly at the coast (Chaitanya et al., 2014) and a case study using SMAP data (Fournier et al., 2017). It also confirms that the IOD is the dominant contributor to BoB SSS interannual variability, as suggested from in situ observations (Pant et al., 2015), modelling (Akhil et al., 2016a) or a case study with SMAP data (Fournier et al., 2017). Our results also show a clear link between those SSS anomalies and the EICC modulation in response to the IOD remote influence through coastal Kelvin wave circumnavigating the $\mathrm{BoB}$, confirming the modelling results of Akhil et al. (2016a).

But our results also illustrate that, with $43 \%$ of explained variance, the IOD is not the only phenomenon to control the boreal fall BoB SSS anomalies. Akhil et al. (2016a) modelling study found a second EOF mode (16\% of the total variance) associated with local SSS anomalies in the northern BoB in response to GangesBrahmaputra River discharge variations. While those discharge variations seem to qualitatively match some of the deviations from the expected IOD signals over the 
period we consider (Fig. 14), the higher order EOFs of the SMOS data or a regression to Ganges Brahmaputra runoff data do not reveal any consistent signal with those discussed by Akhil et al. (2016a). We suspect that this is because the SMOS satellite record is still too short to extract the weaker-amplitude variability (relative to the IOD signal) associated with the Ganges-Brahmaputra river discharge variations. We also find possible influences of mesoscale eddies in modulating the SSS interannual signals along the East Indian coast, consistent with Fournier et al. (2017). Finally, wind intensity may also partly control SSS variations through their impact on vertical mixing, which has been shown to have a prominent vertical mixing processes in eroding the upper-ocean salinity stratification in the BoB (Akhil et al., 2014, 2016a).

We have attempted a budget approach to estimate the processes that explain the seasonal and interannual variability of SSS more quantitatively. We were however not able to close the budget, and we suspect that this is associated with the large uncertainties on the mixed layer depth estimate, that translate into large uncertainties on the estimation of the effect of rain and runoff freshwater fluxes. We hence think that an approach combining modelling and a validation by in situ observations would currently be the best approach to explain the mechanisms of SSS variability. The good agreement between the SMOS SSS seasonal cycle and that described by Akhil et al. (2014) and with the IOD-induced SSS signals in Akhil et al. (2016a) hence suggest that advection is the main process that induces the seasonal southward expansion of the Northern BoB freshwater along the East Indian coast and its interannual modulation. The existence of a second mode of interannual variability of the northern $\mathrm{BoB}$, in relation with GangesBrahmaputra runoff variations in Akhil et al. (2016a) modeling study yet has to be confirmed from direct observations. Future research, relying on the synergy between satellite and in situ observations along with modeling will be essential in order to tackle 
and answer those scientific questions.

A first step in that direction is the recent release of a merged dataset, that combines the SMOS, Aquarius and SMAP satellite retrievals into a single SSS dataset, as part of the Climate Change Initiative (CCI) of the European Space Agency (ESA). A description of this dataset and its data are both available from http://cci.esa.int/salinity for details. The CCI SSS dataset has the advantage of providing calibrated global SSS fields over a long 9-year period (2010-2018), as SMOS, but also to further reduce SSS errors by also using the Aquarius and SMAP data. Figure 16 provides a first evaluation of the quality of this product for the $\mathrm{BoB}$, by comparing its fit to co-located in situ data over the SMOS-new, Aquarius and SMAP data periods. Note that, as for Figure 5, only common data samples to each pair of datasets are used to compute the statistics in each panel of Figure 16. This analysis demonstrates that the CCI-SSS product performs better than any of the single-satellite datasets over their common period. This is also the case when this analysis is performed for the BoB subregions on Figure $2 b$ (not shown). This analysis indicates that CCI-SSS product is likely to be the best alternative to describe and understand the BoB SSS variability in future studies. As this dataset becomes longer, it will allow an increasingly accurate description of the BoB SSS interannual variability. 
Acknowledgments. The authors thank CNES (“Centre National d'Etudes Spatiales”) for

717 the funding support to this Research (project "TOSCA SMOS-Ocean"). The authors

718 thank Stéphane Marchand for his help in handling SMOS data. We also thank IRD

719 ("Institut de Recherche pour le Développement") for the financial support to the

720 collaboration on Indian Ocean research with the CSIR-NIO ("CSIR- National Institute

721 of Oceanography, India"). AVP thank the Director of CSIR-NIO for his encouragement.

722 ML and FP are grateful to "Indo-French Cell for Water Sciences". Keerthi MG is

723 supported through a postdoctoral fellowship from CNES. This is NIO contribution

724 number $\mathrm{xxxx}$. 


\section{References}

Akhil, V.P., Durand, F., Lengaigne, M., Vialard, J., Keerthi, M.G., Gopalakrishna, V.V., Deltel, C., Papa, F. and de Boyer Montégut, C., 2014. A modeling study of the processes of surface salinity seasonal cycle in the Bay of Bengal. Journal of Geophysical Research: Oceans, 119(6), pp.3926-3947.

Akhil, V.P., Lengaigne, M., Vialard, J., Durand, F., Keerthi, M.G., Chaitanya, A.V.S., Papa, F., Gopalakrishna, V.V. and de Boyer Montégut, C., 2016a. A modeling study of processes controlling the Bay of Bengal sea surface salinity interannual variability. Journal of Geophysical Research: Oceans, 121(12), pp.8471-8495.

Akhil, V.P., Lengaigne, M., Durand, F., Vialard, J., Chaitanya, A.V.S., Keerthi, M.G., Gopalakrishna, V.V., Boutin, J. and de Boyer Montégut, C., 2016b. Assessment of seasonal and year-to-year surface salinity signals retrieved from SMOS and Aquarius missions in the Bay of Bengal. International Journal of Remote Sensing, 37(5), pp.1089-1114.

Annamalai, H., Murtugudde, R., Potemra, J., Xie, S. P., Liu, P., \& Wang, B. (2003). Coupled dynamics over the Indian Ocean: Spring initiation of the zonal mode. Deep Sea Research Part II: Topical Studies in Oceanography, 50(12-13), 23052330 .

Anterrieu, E., Suess, M., Cabot, F., Spurgeon, P., and Khazâal, A., 2015. An Additive Mask Correction Approach for Reducing the Systematic Floor Error in Imaging Radiometry by Aperture Synthesis. IEEE Geoscience and Remote Sensing Letters, vol. 12, no. 7, pp. 944 1441-1445, doi: 10.1109/LGRS.2015.2406912.

Antonov, J.I., Seidov, D., Boyer, T. P., Locarnini, R. A., Mishonov, A. V., Garcia, H. E., Baranova, O. K., Zweng, M. M. and Johnson, D. R., 2010. World Ocean Atlas 2009, Volume 2: Salinity, edited by S. Levitus, 184 pp., U.S. Govt. Print. Off., Washington, D.C. Aquarius User Guide, Document \# JPL D-70012, National Aeronautics and Space Administration, Physical Oceanography Distributed Active Archive Center (PO.DAAC), Jet Propulsion Laboratory, 41 pp., 2011.

Aparna, S.G., McCreary, J.P., Shankar, D. and Vinayachandran, P.N., 2012. Signatures 
of Indian Ocean Dipole and El Niño-Southern Oscillation events in sea level variations in the Bay of Bengal. Journal of Geophysical Research: Oceans, 117(C10).

Benshila, R., Durand, F., Masson, S., Bourdallé-Badie, R., de Boyer Montégut, C., Papa, F. and Madec, G., 2014. The upper Bay of Bengal salinity structure in a highresolution model. Ocean Modelling, 74, 36-52.

Boutin, J., Martin, N., Reverdin, G., Yin, X. and Gaillard, F., 2013. Sea surface freshening inferred from SMOS and ARGO salinity: impact of rain. Ocean Science, 9(1), 183-192

Boutin, J.,Vergely, J.-L. and Khvorostyanov, D., 2018. SMOS SSS L3 maps generated by CATDS CEC LOCEAN. debias V3.0. SEANOE. http://doi.org/10.17882/52804\#57467

Boyer, T.P., Baranova, O.K., Coleman, C., Garcia, H.E., Grodsky, A., Locarnini, R.A., Mishonov, A.V., Paver, C.R., Reagan, J.R., Seidov, D., Smolyar, I.V., Weathers, K.W. and Zweng, M.M., 2018. World Ocean Database 2018. A. V. Mishonov, Technical Editor, NOAA Atlas NESDIS 87.

Chaitanya, A.V.S., Lengaigne, M., Vialard, J., Gopalakrishna, V.V., Durand, F., Kranthikumar, C., Amritash, S., Suneel, V., Papa, F. and Ravichandran, M., 2014. Salinity measurements collected by fishermen reveal a "river in the sea" flowing along the eastern coast of India. Bulletin of the American Meteorological Society, 95(12), pp.1897-1908.

Chaitanya, A.V.S., Durand, F., Mathew, S., Gopalakrishna, V.V., Papa, F., Lengaigne, M., Vialard, J., Kranthikumar, C. and Venkatesan, R., 2015. Observed year-toyear sea surface salinity variability in the Bay of Bengal during the 2009-2014 period. Ocean Dynamics, 65(2), pp.173-186.

Chatterjee, A., Shankar, D., Shenoi, S.S.C., Reddy, G.V., Michael, G.S., Ravichandran, M., Gopalkrishna, V.V., Rao, E.R., Bhaskar, T.U. and Sanjeevan, V.N., 2012. A new atlas of temperature and salinity for the North Indian Ocean. Journal of Earth System Science, 121(3), pp.559-593. 
Currie, J.C., M. Lengaigne, J. Vialard, D.M. Kaplan, O. Aumont, S.W.A. Naqvi and O. Maury, 2013: Indian Ocean Dipole and El Niño/Southern Oscillation impacts on regional chlorophyll anomalies in the Indian Ocean, Biogeosciences, 10, 66776698.

de Boyer Montégut, C., Mignot, J., Lazar, A. and Cravatte, S., 2007. Control of salinity on the mixed layer depth in the world ocean: 1. General description. Journal of Geophysical Research: Oceans, 112(C6).

Doi, T., Behera, S. K., \& Yamagata, T., 2020. Predictability of the super IOD event in 2019 and its link with El Niño Modoki. Geophysical Research Letters, doi : 10.1029/2019GL086713.

Dommenget, D., \& Jansen, M. (2009). Predictions of Indian Ocean SST indices with a simple statistical model: A null hypothesis. Journal of climate, 22(18), 4930-4938.

Ducet, N., Le Traon, P. Y. and Reverdin, G., 2000. Global high-resolution mapping of ocean circulation from TOPEX/POSEIDON and ERS-1 and -2, J. Geophys. Res.: Oceans, 105(C8), 19,477-19,498.

Durand, F., Shankar, D., Birol, F. and Shenoi, S.S.C., 2009. Spatiotemporal structure of the East India Coastal Current from satellite altimetry. Journal of Geophysical Research: Oceans, 114(C2).

Fore A., Yueh, S., Tang, W. and Hayashi, A., 2017. SMAP Salinity and Wind Speed Data User's Guide Version 4.0, Jet Propulsion Laboratory California Institute of Technology.

Fournier, S., Vialard, J., Lengaigne, M., Lee, T., Gierach, M.M. and Chaitanya, A.V.S., 2017. Modulation of the Ganges- Brahmaputra River plume by the Indian Ocean dipole and eddies inferred from satellite observations. Journal of Geophysical Research: Oceans, 122(12), pp.9591-9604.

Garcia, H. E., Boyer, T. P., Locarnini, R. A., Baranova, O. K. and Zweng, M. M., 2018. World Ocean Database 2018: User's Manual (prerelease). A.V. Mishonov, Technical Ed., NOAA, Silver Spring, MD (Available at https://www.NCEI.noaa.gov/OC5/WOD/pr_wod.html). 
Gaillard, F., Reynaud, T., Thierry, V., Kolodziejczyk, N. and von Schuckmann, K., 2016. In situ-based reanalysis of the global ocean temperature and salinity with ISAS: Variability of the heat content and steric height. Journal of Climate, 29(4), pp.1305-1323.

Hareesh Kumar, P.V., Mathew, B., Kumar, M.R.R., Rao, A.R., Jagadeesh, P.S.V., Radhakrishnan, K.G. and Shyni, T.N., 2013. 'Thermohaline front'off the east coast of India and its generating mechanism. Ocean Dynamics, 63(11-12), pp.11751180.

Keerthi, M. G., M. Lengaigne, J. Vialard, C. de Boyer Montégut and P.M. Muraleedharan, 2013: Interannual variability of the Tropical Indian Ocean mixed layer depth, Clim. Dyn., 40, 743-759.

Krishnamohan, K.S., Vialard, J., Lengaigne, M., Masson, S., Samson, G., Pous, S., Neetu, S., Durand, F., Shenoi, S.S.C., Madec, G., Is there an effect of Bay of Bengal salinity on the northern Indian Ocean climatological rainfall?, Deep-Sea Research Part II (2019), doi: https:// doi.org/10.1016/j.dsr2.2019.04.003

Lagerloef, G., Colomb, F.R., Le Vine, D., Wentz, F., Yueh, S., Ruf, C., Lilly, J., Gunn, J., Chao, Y.I., DECHARON, A. and Feldman, G., 2008. The Aquarius/SAC-D mission: Designed to meet the salinity remote-sensing challenge. Oceanography, 21(1), pp.68-81.

McPhaden, M.J., Meyers, G., Ando, K., Masumoto, Y., Murty, V.S.N., Ravichandran, M., Syamsudin, F., Vialard, J., Yu, L. and Yu, W., 2009. RAMA: the research moored array for African-Asian-Australian monsoon analysis and prediction. Bulletin of the American Meteorological Society, 90(4), pp.459-480.

Meissner, T., Wentz, F. and Le Vine, D., 2018. The salinity retrieval algorithms for the NASA Aquarius version 5 and SMAP version 3 releases. Remote Sensing, 10(7), p.1121.

Neetu, S., Lengaigne, M., Vincent, E.M., Vialard, J., Madec, G., Samson, G., Ramesh Kumar, M.R. and Durand, F., 2012. Influence of upper- ocean stratification on tropical cyclone- induced surface cooling in the Bay of Bengal. Journal of 
Neetu, S., Lengaigne, M., Vialard, J., Samson, G., Masson, S., Krishnamohan, K.S. and Suresh, I., 2019. Premonsoon/Postmonsoon Bay of Bengal Tropical Cyclones Intensity: Role of Air- Sea Coupling and Large- Scale Background State. Geophysical Research Letters, 46(4), pp.2149-2157.

Oliva, R., Daganzo, E., Richaume, P., Kerr, Y., Cabot, F., Soldo, Y., Anterrieu, E., Reul, N., Gutierrez, A., Barbosa, J. and Lopes, G., 2016. Status of Radio Frequency Interference (RFI) in the 1400-1427 MHz passive band based on six years of SMOS mission. Remote sensing of environment, 180, pp.64-75.

Pant, V., Girishkumar, M.S., Udaya Bhaskar, T.V.S., Ravichandran, M., Papa, F. and Thangaprakash, V.P., 2015. Observed interannual variability of near- surface salinity in the B ay of B engal. Journal of Geophysical Research: Oceans, 120(5), pp.3315-3329.

Papa, F., Bala, S.K., Pandey, R.K., Durand, F., Gopalakrishna, V.V., Rahman, A. and Rossow, W.B., 2012. Ganga- Brahmaputra river discharge from Jason- 2 radar altimetry: An update to the long- term satellite- derived estimates of continental freshwater forcing flux into the Bay of Bengal. Journal of Geophysical Research: Oceans, 117(C11).

Papa, F., Durand, F., Rossow, W.B., Rahman, A. and Bala, S.K., 2010. Satellite altimeter- derived monthly discharge of the Ganga- Brahmaputra River and its seasonal to interannual variations from 1993 to 2008. Journal of Geophysical Research: Oceans, 115(C12).

Prasanna Kumar, S., Muraleedharan, P.M., Prasad, T.G., Gauns, M., Ramaiah, N., De Souza, S.N., Sardesai, S. and Madhupratap, M., 2002. Why is the Bay of Bengal less productive during summer monsoon compared to the Arabian Sea?. Geophysical Research Letters, 29(24), pp.88-1.

Rao, R.R. and Sivakumar, R., 2003. Seasonal variability of sea surface salinity and salt budget of the mixed layer of the north Indian Ocean. Journal of Geophysical Research: Oceans, 108(C1), pp.9-1. 
Reul, N., Fournier, S., Boutin, J., Hernandez, O., Maes, C., Chapron, B., Alory, G., Quilfen, Y., Tenerelli, J., Morisset, S. and Kerr, Y., 2014. Sea surface salinity observations from space with the SMOS satellite: A new means to monitor the marine branch of the water cycle. Surveys in Geophysics, 35(3), pp.681-722.

Roemmich, D., Johnson, G. C., Riser, S., Davis, R., Gilson, J., Owens, W. B., Garzoli, S. L., Schmid, C. and Ignaszewski, M., 2009. The Argo Program: Observing the global ocean with profiling floats. Oceanography, 22(2), 34-43.

Saji, N.H., Goswami, B.N., Vinayachandran, P.N. and Yamagata, T., 1999. A dipole mode in the tropical Indian Ocean. Nature, 401(6751), p.360.

Sengupta, D., Goddalehundi, B.R. and Anitha, D.S., 2008. Cyclone- induced mixing does not cool SST in the post- monsoon north Bay of Bengal. Atmospheric Science Letters, 9(1), pp.1-6.

Sengupta, D., Bharath Raj, G.N., Ravichandran, M., Sree Lekha, J. and Papa, F., 2016. Near- surface salinity and stratification in the north Bay of Bengal from moored observations. Geophysical Research Letters, 43(9), pp.4448-4456.

Shaaban, A. A., \& Roundy, P. E. (2017). OLR perspective on the Indian Ocean Dipole with application to East African precipitation. Quarterly Journal of the Royal Meteorological Society, 143(705), 1828-1843.

Shenoi, S.S.C., Shankar, D. and Shetye, S.R., 2002. Differences in heat budgets of the near- surface Arabian Sea and Bay of Bengal: Implications for the summer monsoon. Journal of Geophysical Research: Oceans, 107(C6), pp.5-1.

Sherin, V.R., Durand, F., Gopalkrishna, V.V., Anuvinda, S., Chaitanya, A.V.S., Bourdallé-Badie, R., and Papa, F., 2018. Signature of Indian Ocean Dipole on the western boundary current of the Bay of Bengal. Deep Sea Research Part I: Oceanographic Research Papers, 136, 91-106.

Shetye, S.R., 1993. The movement and implications of the Ganges-Bramhaputra runoff on entering the. Current Science, 64(1), 32-38.

Shetye, S. R., Gouveia, A, D., Shankar, D., Michael, G. S. and Nampoothiri, G., 1996. 
Hydrography and circulation of the western Bay of Bengal during the Northeast Monsoon, Journal of Geophysical Research, 101, 14,011 - 14,025.

Sudre, J., Maes, C. and Garçon, V., 2013. On the global estimates of geostrophic and Ekman surface currents. Limnology and Oceanography: Fluids and Environments, 3(1), pp.1-20.

Subrahmanyam, B., Grunseich, G. and Nyadjro, E.S., 2012. Preliminary SMOS salinity measurements and validation in the Indian Ocean. IEEE Transactions on Geoscience and Remote Sensing, 51(1), pp.19-27.

Suresh, I., Vialard, J., Lengaigne, M., Izumo, T., Parvathi, V. and Muraleedharan, P.M., 2018. Sea level interannual variability along the west coast of India. Geophysical Research Letters, 45(22), pp.12-440.

Thadathil, P., Suresh, I., Gautham, S., Prasanna Kumar, S., Lengaigne, M., Rao, R.R., Neetu, S. and Hegde, A., 2016. Surface layer temperature inversion in the Bay of Bengal: Main characteristics and related mechanisms. Journal of Geophysical Research: Oceans, 121(8), pp.5682-5696.

Webster, P. J., Moore, A. M. , Loschnigg, J. P. and Leben, R. R., 1999. Coupled ocean- atmosphere dynamics in the Indian Ocean during 1997-98, Nature, 401, 356-360, doi:10.1038/43848.

Wijesekera, H.W., Shroyer, E., Tandon, A., Ravichandran, M., Sengupta, D., Jinadasa, S.U.P., Fernando, H.J., Agrawal, N., Arulananthan, K., Bhat, G.S. and Baumgartner, M., 2016. ASIRI: An ocean-atmosphere initiative for Bay of Bengal. Bulletin of the American Meteorological Society, 97(10), pp.1859-1884.

Yueh, S.H., Tang, W., Fore, A.G., Neumann, G., Hayashi, A., Freedman, A., Chaubell, J. and Lagerloef, G.S., 2013. L-band passive and active microwave geophysical model functions of ocean surface winds and applications to Aquarius retrieval. IEEE Transactions on Geoscience and Remote Sensing, 51(9), pp.4619-4632.

Yueh, S., Tang, W., Fore, A., Hayashi, A., Song, Y.T. and Lagerloef, G., 2014. Aquarius geophysical model function and combined active passive algorithm for ocean surface salinity and wind retrieval. Journal of Geophysical Research: Oceans, 
Zweng, M. M, Reagan, J. R., Seidov, D., Boyer, T. P., Locarnini, R. A., Garcia, H. E., Mishonov, A. V., Baranova, O. K., Paver, C. R., Weathers, K. W., Smolyar, I. (2018): World Ocean Atlas 2018, Volume 2: Salinity. NOAA Atlas NESDIS (Vol. 82). https://www.nodc.noaa.gov/OC5/woa18/pubwoa18.html 


\begin{tabular}{|c|c|c|c|c|c|}
\hline $\begin{array}{l}\text { Name } \\
\text { in this } \\
\text { paper }\end{array}$ & Obtained from & $\begin{array}{l}\text { Product } \\
\text { version }\end{array}$ & $\begin{array}{l}\text { Temporal } \\
\text { resolution }\end{array}$ & $\begin{array}{l}\text { Spatial grid } \\
\text { resolution }\end{array}$ & $\begin{array}{l}\text { Analyze } \\
\text { d period }\end{array}$ \\
\hline $\begin{array}{l}\text { SMOS- } \\
\text { old }\end{array}$ & $\begin{array}{l}\text { https://www.catds.fr/Produ } \\
\text { cts/Available-products- } \\
\text { from-CEC-OS/CEC- } \\
\text { Ifremer-Dataset-V02 }\end{array}$ & $\begin{array}{l}\text { “SSS_SMOS_ } \\
\text { L3_CATDS_C } \\
\text { ECOS_V02”" }\end{array}$ & $\begin{array}{l}\text { 10day running } \\
\text { mean maps } \\
\text { every } 10 \text { days }\end{array}$ & $0.25^{\circ} \mathrm{X} 0.25^{\circ}$ & $\begin{array}{l}\text { May } 2010 \\
\text { to June } \\
2017\end{array}$ \\
\hline $\begin{array}{l}\text { SMOS- } \\
\text { new }\end{array}$ & $\begin{array}{l}\text { https://www.catds.fr/Produ } \\
\text { cts/Available-products- } \\
\text { from-CEC-OS/CEC- } \\
\text { Locean-L3-Debiased-v4 }\end{array}$ & $\begin{array}{l}\text { "L3_DEBIAS_ } \\
\text { LOCEAN_v4” }\end{array}$ & $\begin{array}{l}\text { 9day running } \\
\text { mean maps } \\
\text { every } 4 \text { days }\end{array}$ & $0.25^{\circ} \mathrm{X} 0.25^{\circ}$ & $\begin{array}{l}\text { January } \\
2010 \text { to } \\
\text { September } \\
2019\end{array}$ \\
\hline $\begin{array}{l}\text { Aquariu } \\
\mathrm{S}\end{array}$ & $\begin{array}{l}\text { https://podaac.jpl.nasa.gov/ } \\
\text { dataset/AQUARIUS_L3_S } \\
\text { SS_CAP_7DAY_V5 }\end{array}$ & $\begin{array}{l}\text { "L3m_7D_SCI } \\
-\mathrm{V} 5.0 "\end{array}$ & $\begin{array}{l}\text { 7day running } \\
\text { mean maps } \\
\text { every } 7 \text { days }\end{array}$ & $1^{\circ} \mathrm{X} 1^{\circ}$ & $\begin{array}{l}\text { August } \\
2011 \text { to } \\
\text { June } 2015\end{array}$ \\
\hline SMAP & $\begin{array}{l}\text { https://podaac.jpl.nasa.gov/ } \\
\text { dataset/SMAP_JPL_L3_S } \\
\text { SS_CAP_8DAY- } \\
\text { RUNNINGMEAN_V43 }\end{array}$ & $\begin{array}{l}\text { “L3V4.3_SSS_ } \\
\text { 8DAYS_R130 } \\
80 ”\end{array}$ & $\begin{array}{l}\text { 8day running } \\
\text { mean maps } \\
\text { every day }\end{array}$ & $0.25^{\circ} \mathrm{X} 0.25^{\circ}$ & $\begin{array}{l}\text { April } 2015 \\
\text { to } \\
\text { December } \\
2019\end{array}$ \\
\hline
\end{tabular}

934 Table 1. Sea Surface Salinity products used in the current study. More details on the 935 differences between the two SMOS datasets used in this study can be found on the 936 CATDS (Centre Aval de Traitement des Données SMOS) website at 937 "https://www.catds.fr/content/download/68781/file/OS_L3_products_Differences_and 938 ProsCons.pdf'. 


\begin{tabular}{|c|c|c|c|c|}
\hline Correlation & DMI & SDI & ODI & WDI \\
\hline DMI & $1(1)$ & $0.89(0.86)$ & $0.83(0.74)$ & $0.88(0.78)$ \\
\hline SDI & $0.89(0.86)$ & $1(1)$ & $0.91(0.92)$ & $0.97(0.96)$ \\
\hline
\end{tabular}

940

941

942

943

944

945

946

947

948

949

950

Table 2. Correlation between the four IOD indices used in this study over the 1993-2018 period, with values over the 2010-2018 study period within brackets The DMI index is the SSTA-based index introduced by Saji et al. (1999). ODI (Outgoing longwave radiation-based dipole index) is the alternative index proposed by Shaaban and Roundy (2017). We also propose two indices that focus on the oceanic dynamical response based on sea level anomalies (SDI for Sea level Dipole Index) and zonal wind stress anomalies (WDI for Wind stress Dipole Index). The definition of these four IOD indices is detailed in Figure 3 and in the method section. The correlations provided in this table are all significantly different from zero above the 99\% confidence level, considering each year as an independent sample. 

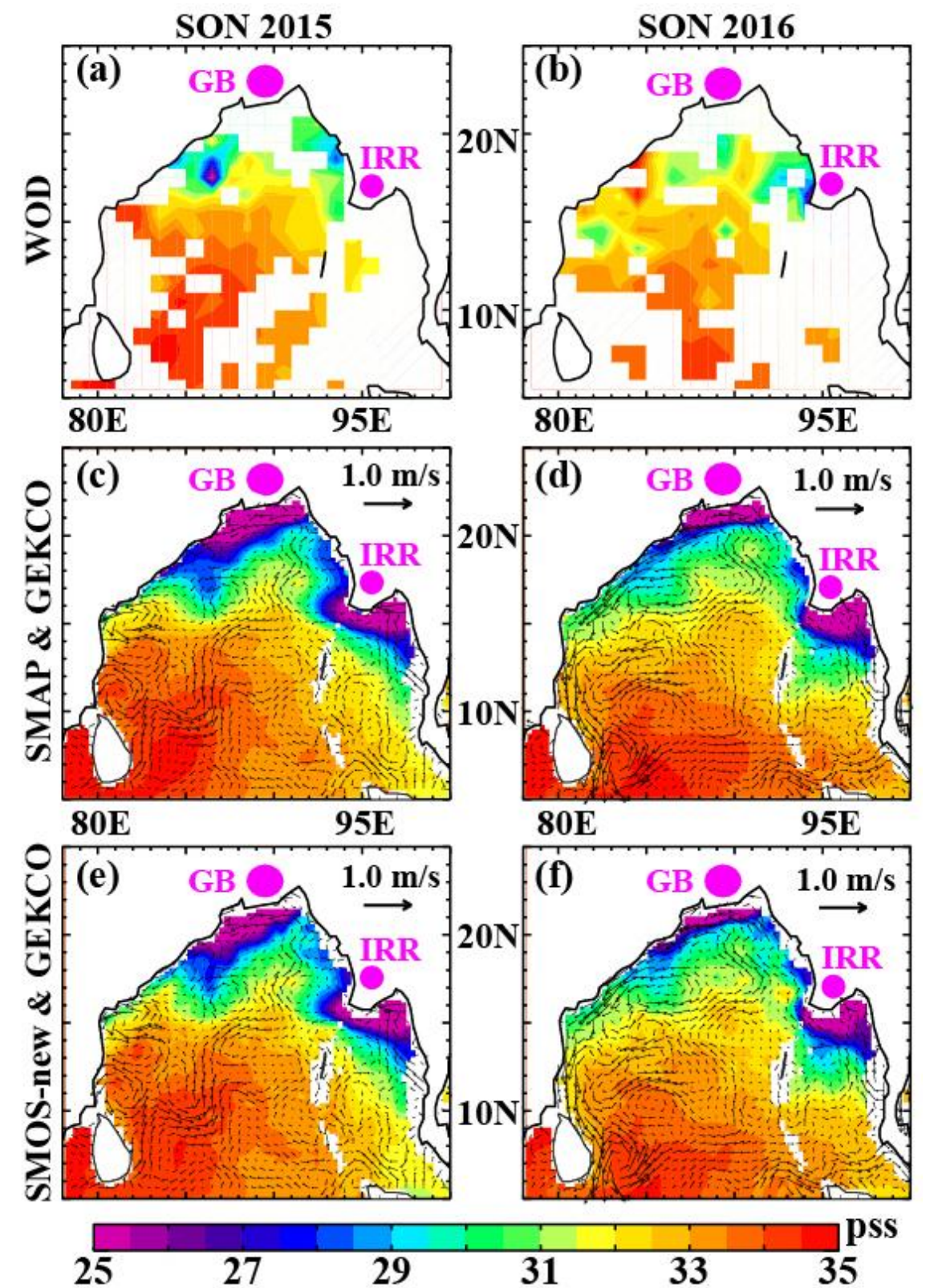

952 Figure 1. September to November (SON) average map of (a, b) World Ocean Data 953 (WOD) sea surface salinity (SSS), (c, d) SMAP SSS (color) and GEKCO currents 954 (vector), (e, f) SMOS-new SSS (color) and GEKCO currents (vector) for ( $\mathbf{1}^{\text {st }}$ column) 9552015 and $\left(2^{\text {nd }}\right.$ column) 2016. The location of the Ganges-Brahmaputra (GB) and 956 Irrawaddy (IRR) estuaries, the two main river systems in to the Bay of Bengal (BoB), 957 are marked on the panels. 


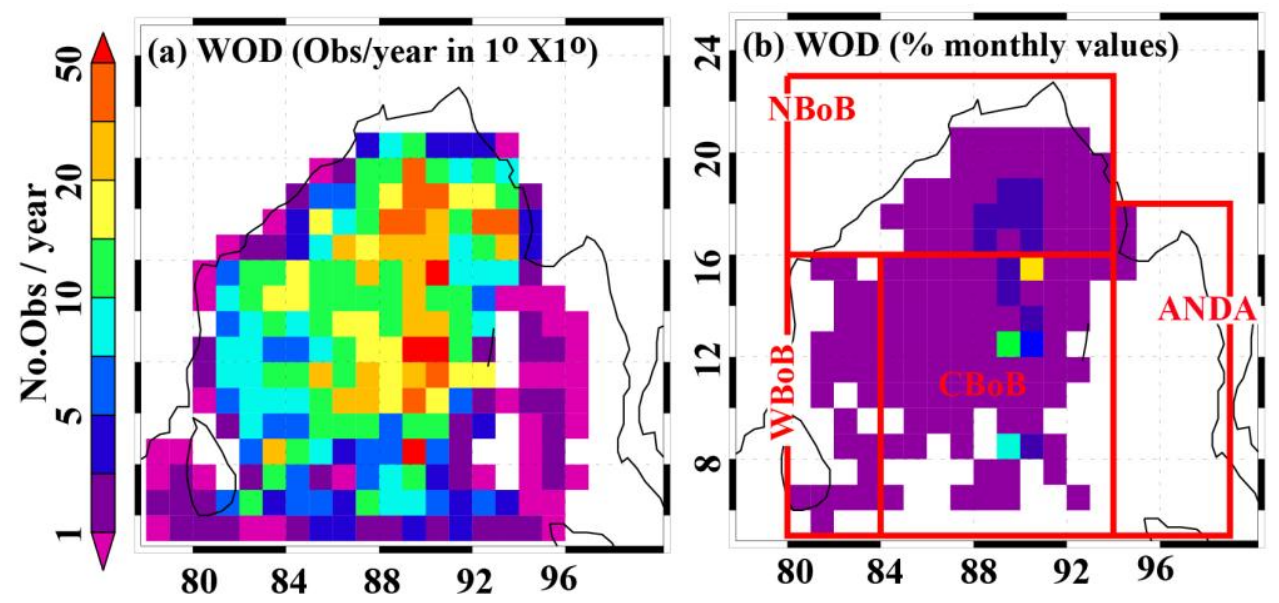

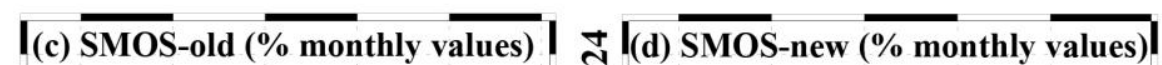
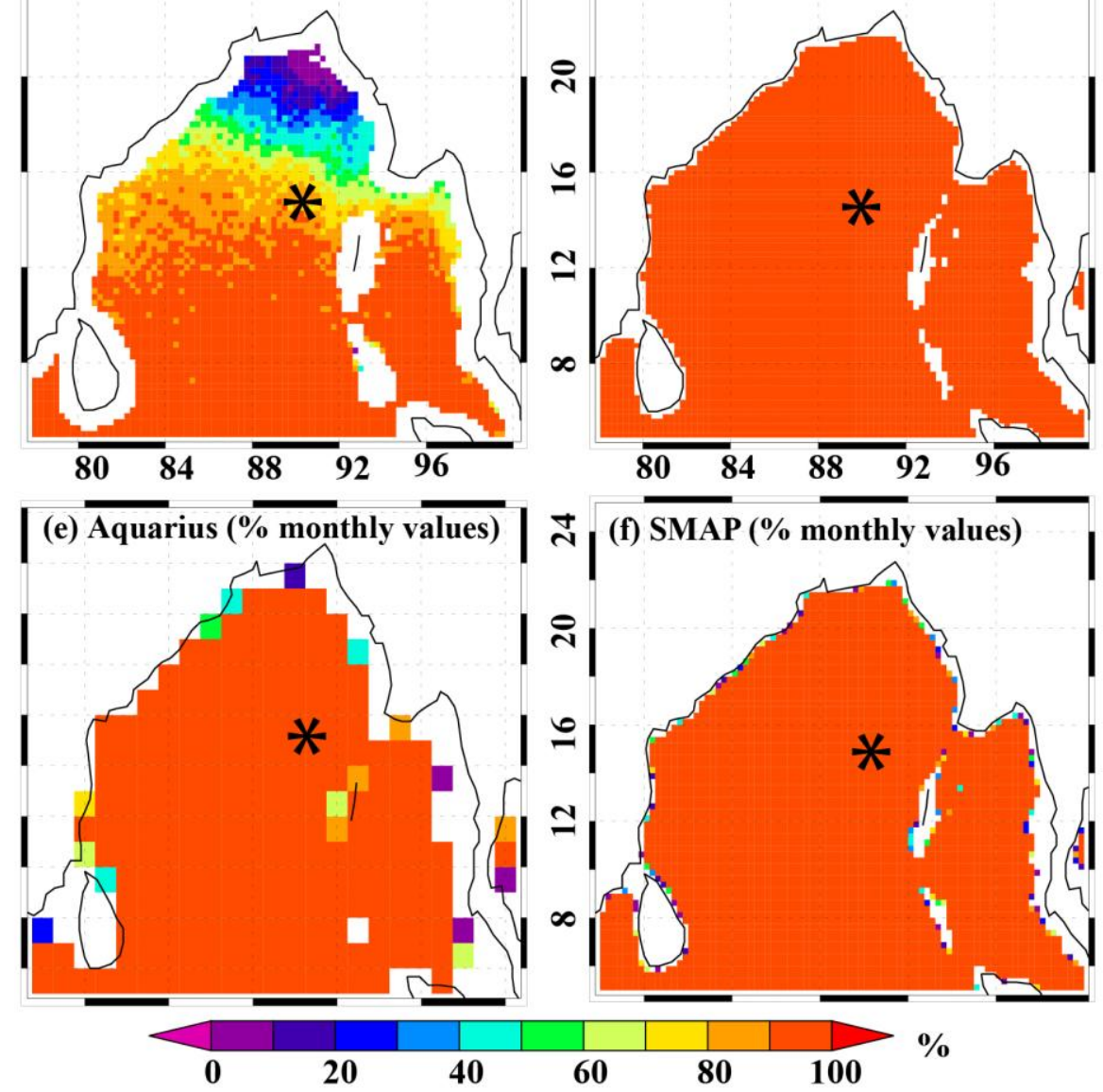

Figure 2. (a) Total number of WOD in situ observations, per year and per $1^{\circ} \mathrm{x} 1^{\circ}$ boxes above $5 \mathrm{~m}$ depth. (b - f) Percent of months with SSS data from (b) WOD (only $1^{\circ} \times 1^{\circ}$ pixels having more than 5 data per month are considered as valid SSS data), (c) SMOSold, (d) SMOS-new, (e) Aquarius and (f) SMAP. See Table 1 for the time period covered by each dataset. The star indicates the $\left[15^{\circ} \mathrm{N}, 90^{\circ} \mathrm{E}\right]$ RAMA mooring location. 

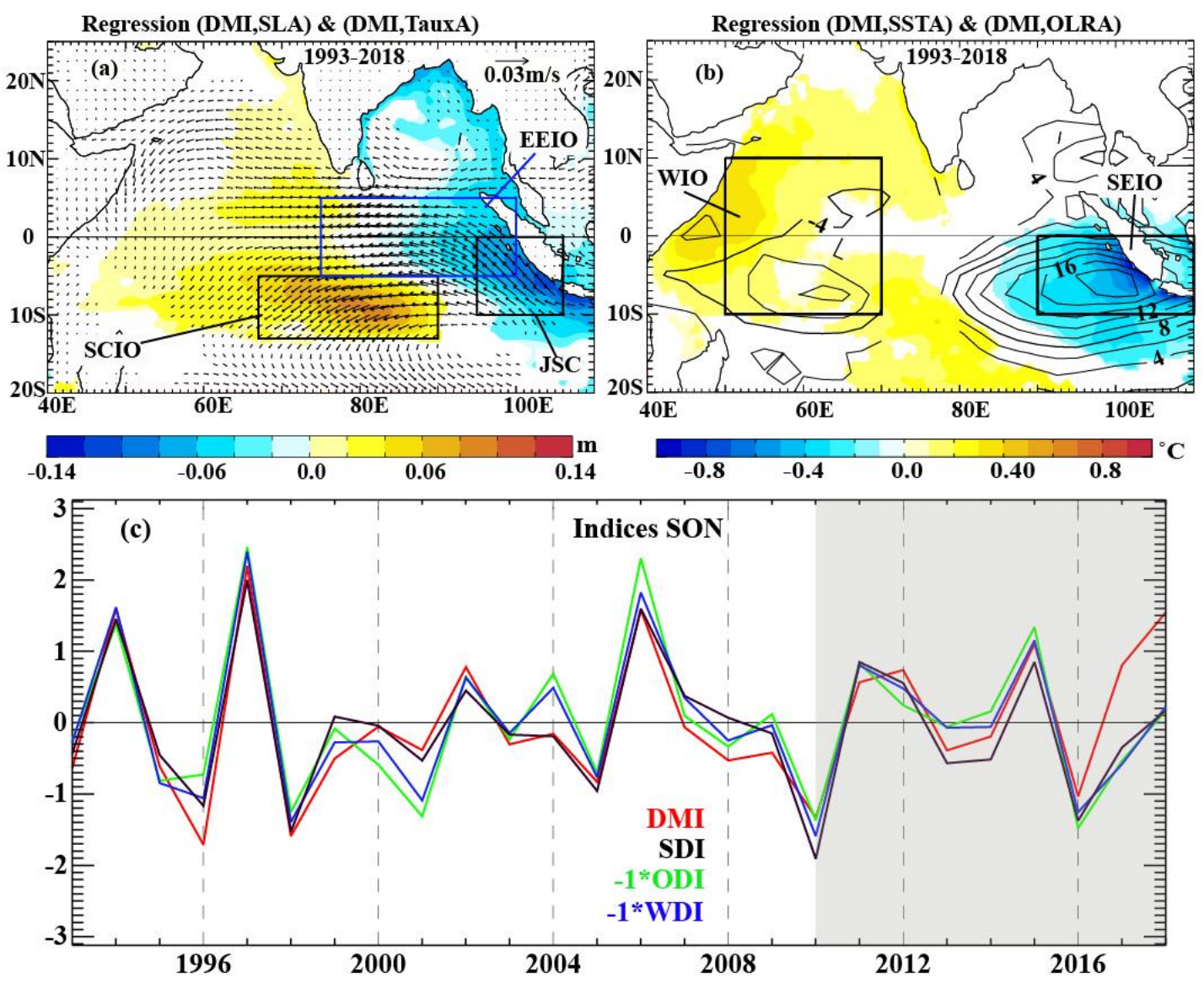

Figure 3. Regression of interannual anomalies of (a) wind stress (vectors) and sea level (colors) and (b) SST (colors) and Outgoing Longwave Radiation (OLR, W.m.' contours) onto the DMI in September-October-November (SON) over the 1993-2018 period. Values are masked only when they are not significantly different from zero at the 90\% confidence level. (c) Time series of the four IOD indices used in this study over 1993-2018 period. The sea level dipole index (SDI) is computed as the SLA difference between the south central Indian Ocean and Java/Sumatra Coast (see black frames on panel a denoted respectively SCIO and JSC). The wind stress dipole index (WDI) is taken as the zonal wind stress averaged over the eastern equatorial Indian Ocean (see blue box denoted EEIO on panel a). The OLR-based index (ODI) is computed as the difference of OLR anomalies between the western Indian Ocean and the southeastern Indian Ocean (see black frames on panel b denoted respectively WIO and SEIO, those are the same boxes as those used to define the DMI by Saji et al. 1999). Correlations between these different indices are provided on Table 2. The shading on panel (c) highlights the 2010-2018 period, for which the interannual variability of Sea Surface Salinity is analyzed in the current paper. 

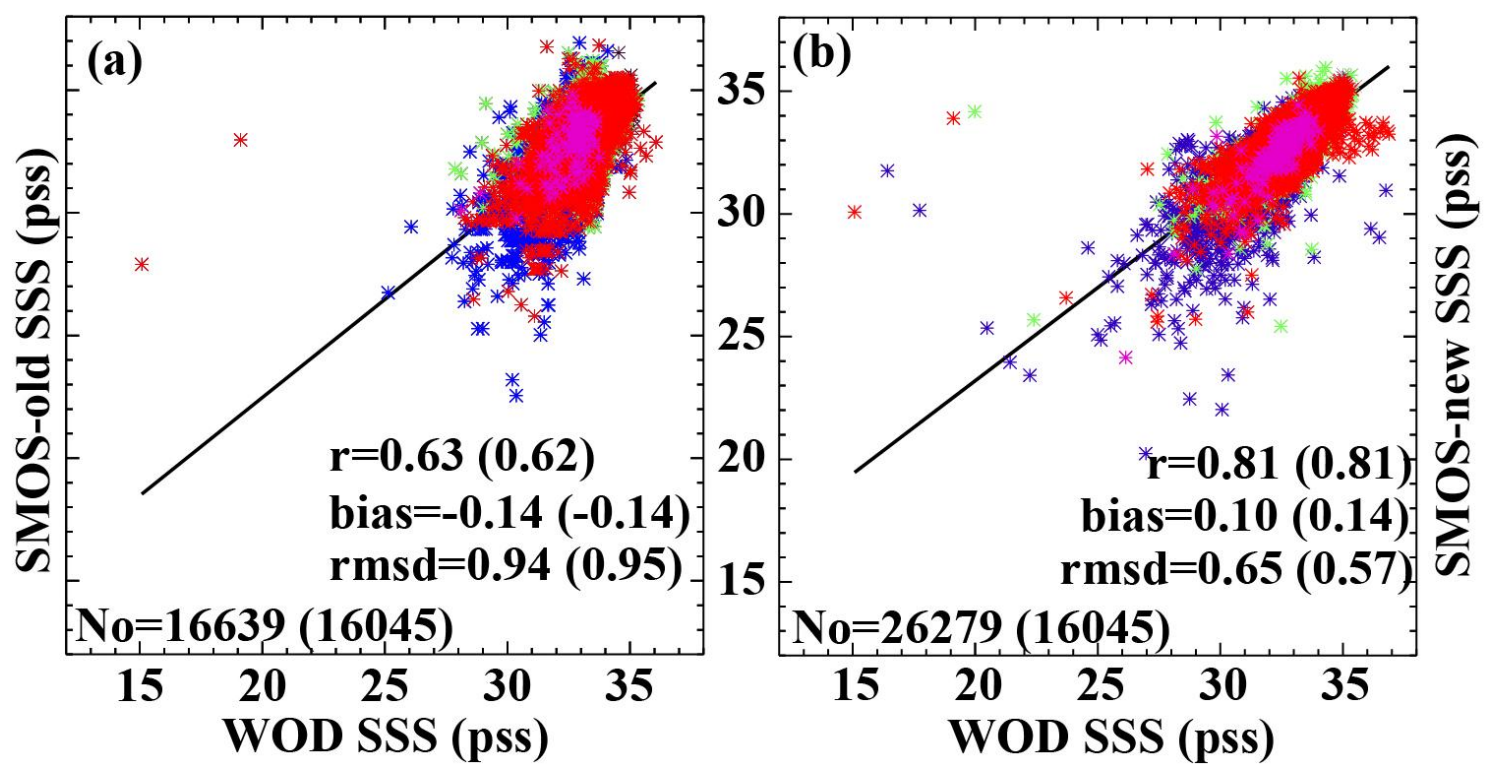

984

985

986

Figure 4. Scatterplot of co-located WOD Bay of Bengal (BoB) SSS against (a) SMOS987 old (2010-2017) and (b) SMOS-new (2010 to 2019). The correlation (r), bias, and root988 mean-square difference (rmsd) to the WOD data are indicated on each panel (the number in brackets provide those statistics for the common period to WOD, SMOS-old and

990 SMOS-new).

991 


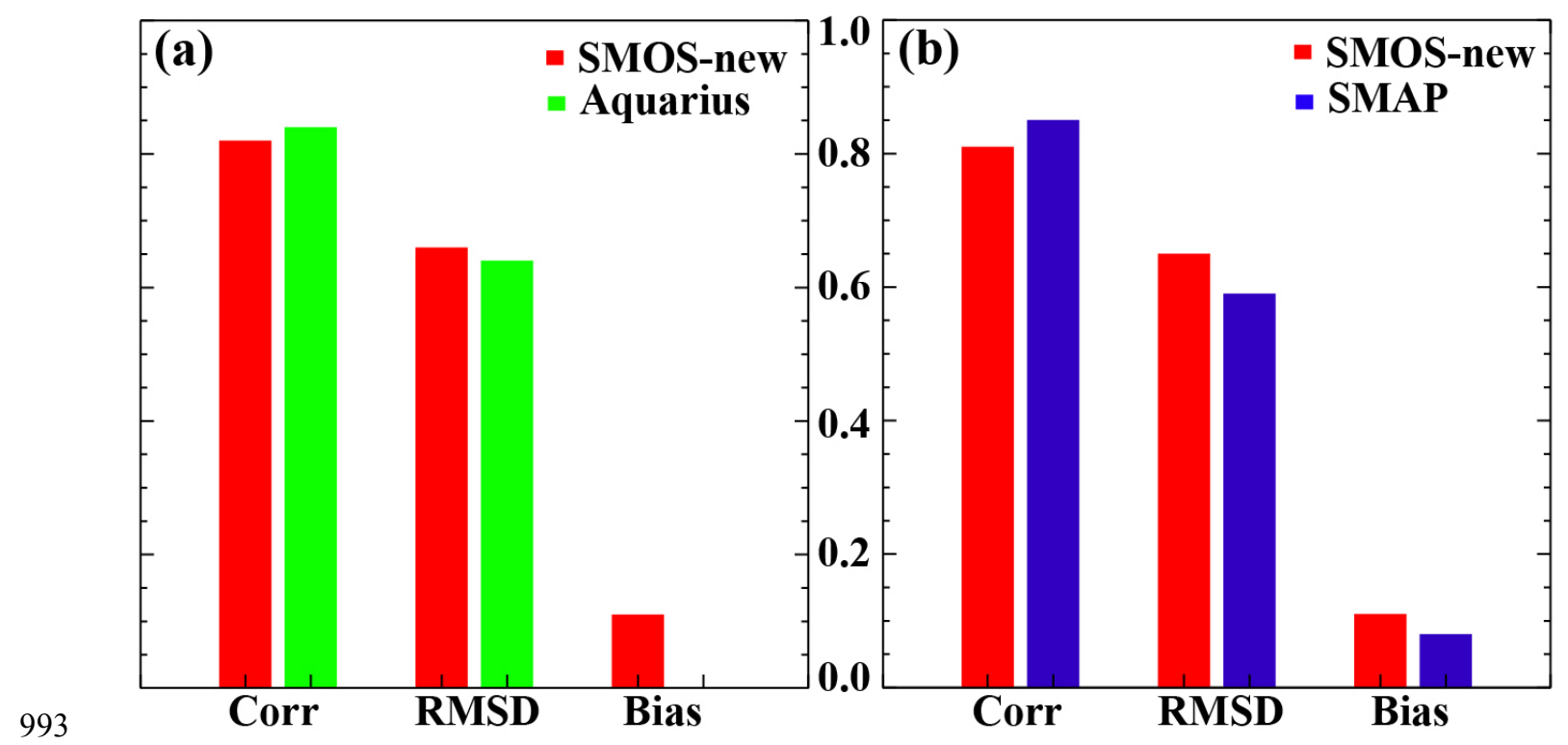

994 Figure 5. (a) Bar diagrams of statistics of comparisons between co-located SMOS-new 995 and Aquarius with in situ data over their common period (August 2011 to June 2015) 996 and over the entire BoB. (b) Same as (a) but for SMOS-new \& SMAP (April 2015 to 997 October 2019). The statistics on this figure are strictly comparable, since both satellite 998 datasets on each panel are compared to their common co-located in situ data sample. The 999 Y-axis scale in the middle is common to both panels. The correlation has no unit, and 1000 the RMSD and bias are in ${ }^{\circ} \mathrm{C}$.

1001 

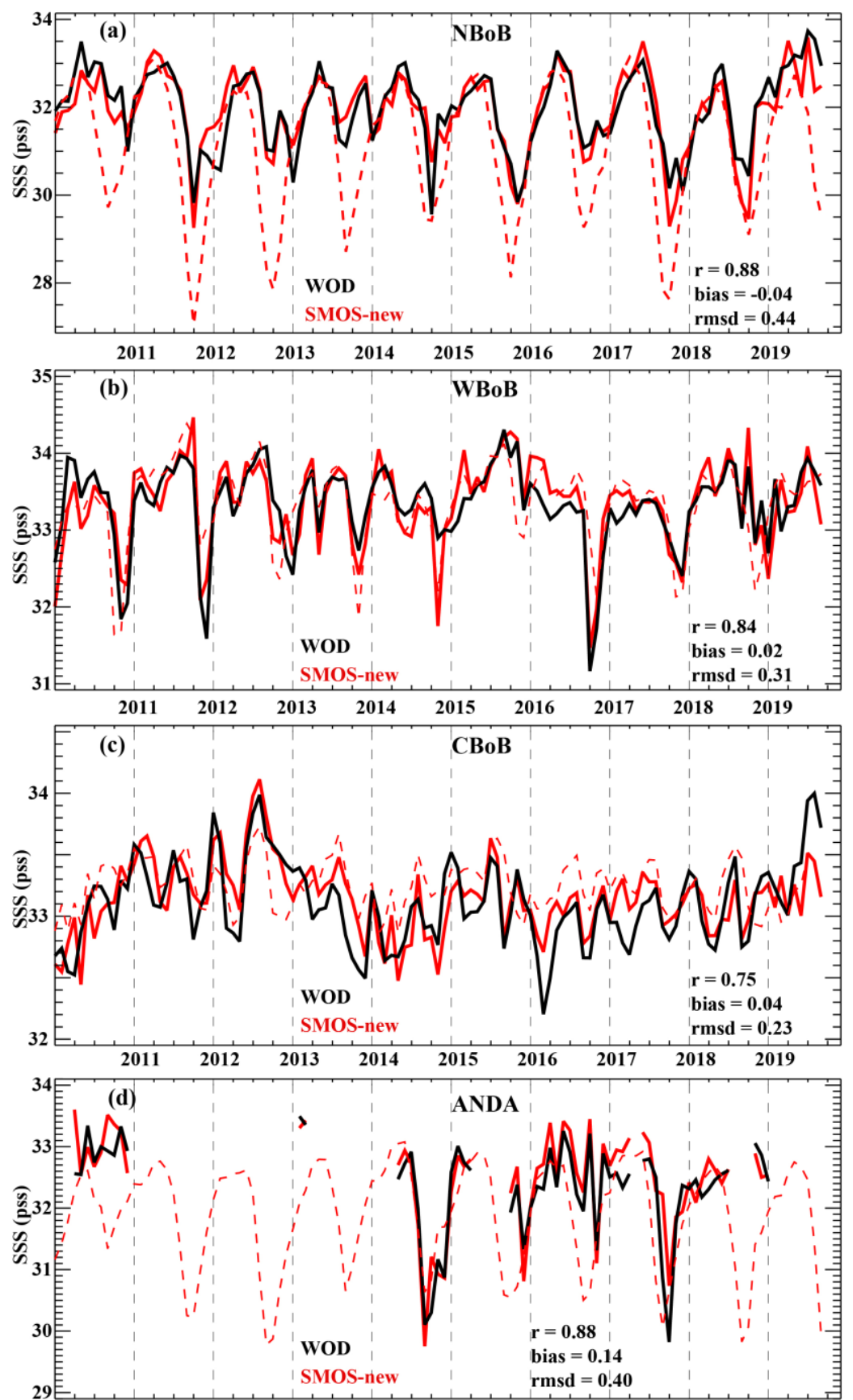

Figure 6. Timeseries of averaged co-located SMOS-new (red continuous line) and WOD SSS (black continuous line) within the (a) $\mathrm{NBoB}$, (b) $\mathrm{WBoB}$, (c) $\mathrm{CBoB}$ and (d) ANDA regions (see figure 2 for their definitions). The corresponding statistics are indicated on each panel (these statistics differ from the ones in Figure 7, because these are based on box-averaged quantities, not on individual co-located measurements). The red dashed curve shows the box averaged SMOS-new data in each region (different from the red full curve because it accounts for values everywhere in the box, not just for colocated values with in situ data). 


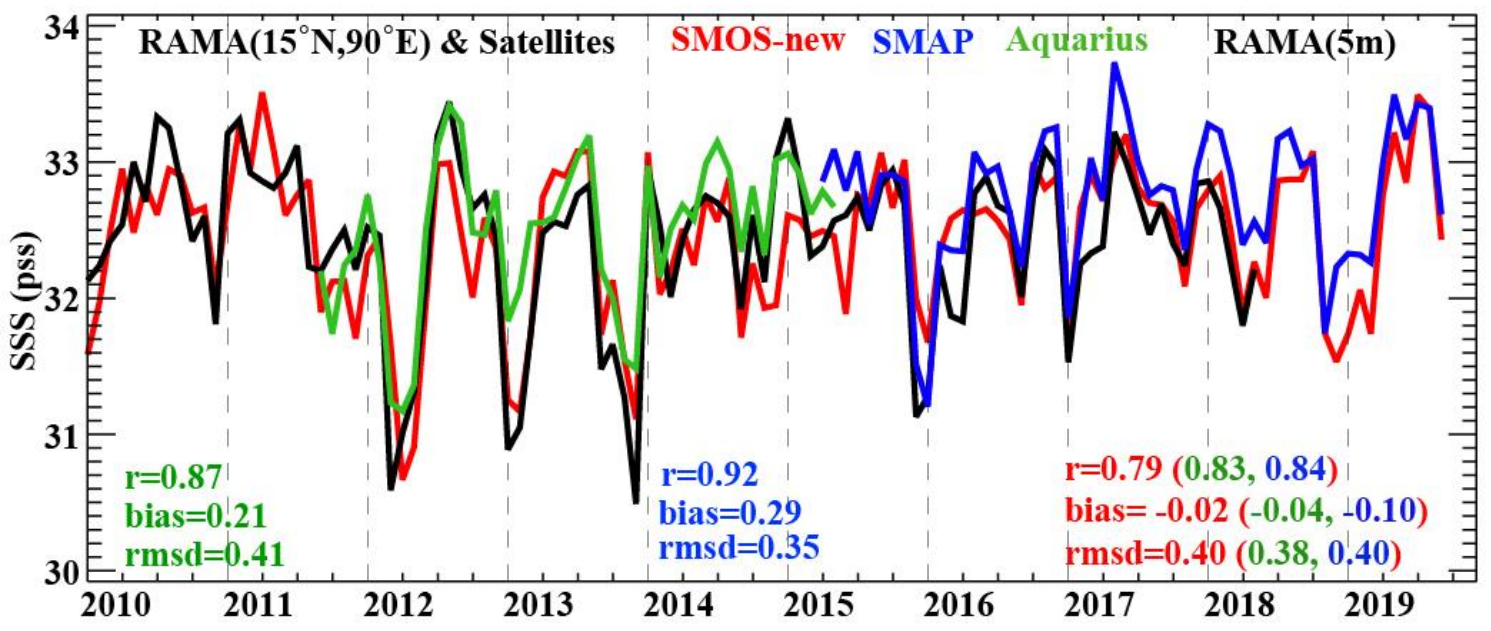

1013 Figure 7. Time series of the salinity at $5 \mathrm{~m}$ depth from the $15^{\circ} \mathrm{N}-90^{\circ} \mathrm{E}$ RAMA mooring 1014 (black) and co-located SMOS-new (red), Aquarius (green) and SMAP (blue) satellite 1015 data. The correlation (r), bias and root-mean-square difference (rmsd) of each dataset to 1016 RAMA are given in red for SMOS-new, green for Aquarius and blue for SMAP. The 1017 number in brackets give the SMOS-new statistics for the period common to Aquarius (in 1018 green) and SMAP (in blue).

1019 

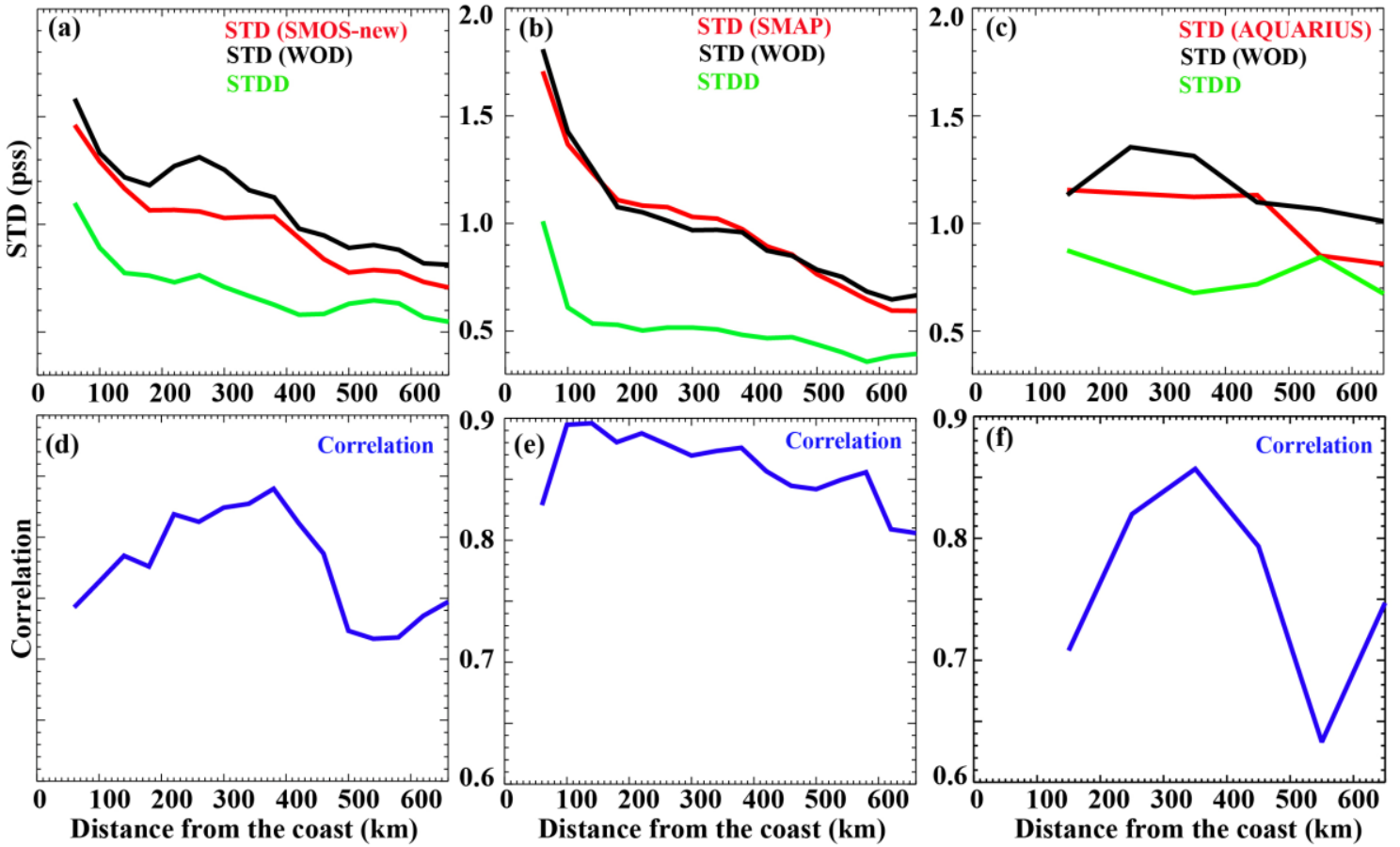

Figure 8. (a) Standard deviation (STD, ${ }^{\circ} \mathrm{C}$ ) of co-located SMOS-new SSS (red) and WOD SSS (black), and standard deviation of their difference (STDD, ${ }^{\circ} \mathrm{C}$, green) as a function of distance to the coast (40-km wide bins) from east coast of India $10^{\circ} \mathrm{N}-20.5^{\circ} \mathrm{N}$ and $78^{\circ} \mathrm{E}-90^{\circ} \mathrm{E}$. (d) Correlation coefficient between SMOS-new SSS (blue) and colocated WOD SSS as a function of distance to the coast (40-km wide bins) from east coast of India $10^{\circ} \mathrm{N}-20.5^{\circ} \mathrm{N}$ and $78^{\circ} \mathrm{E}-90^{\circ} \mathrm{E}$. (b, e) Same as a, d but for SMAP. (c, f) Same as a, d but for Aquarius (but using 100-km wide bins). 

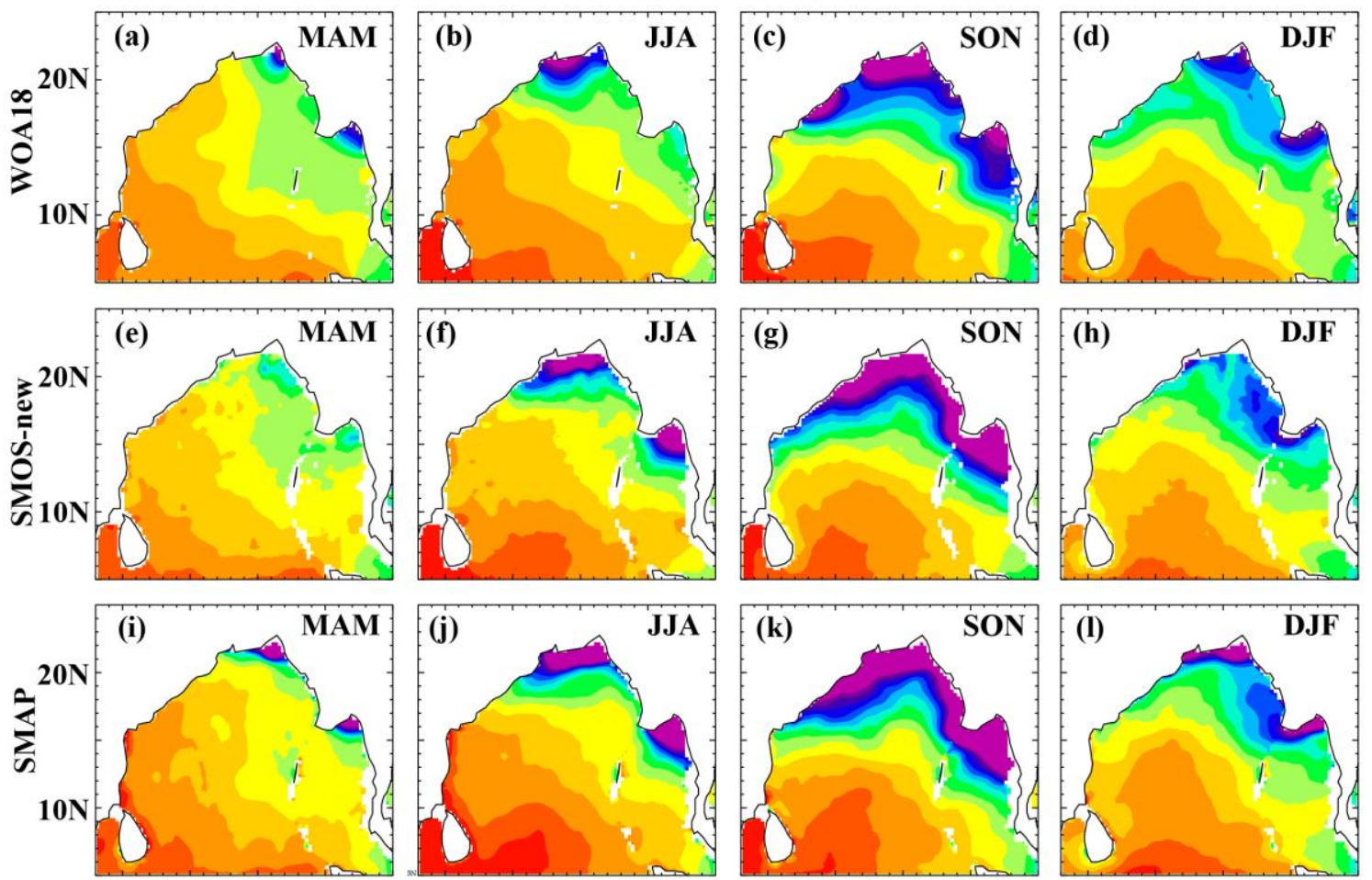

1031
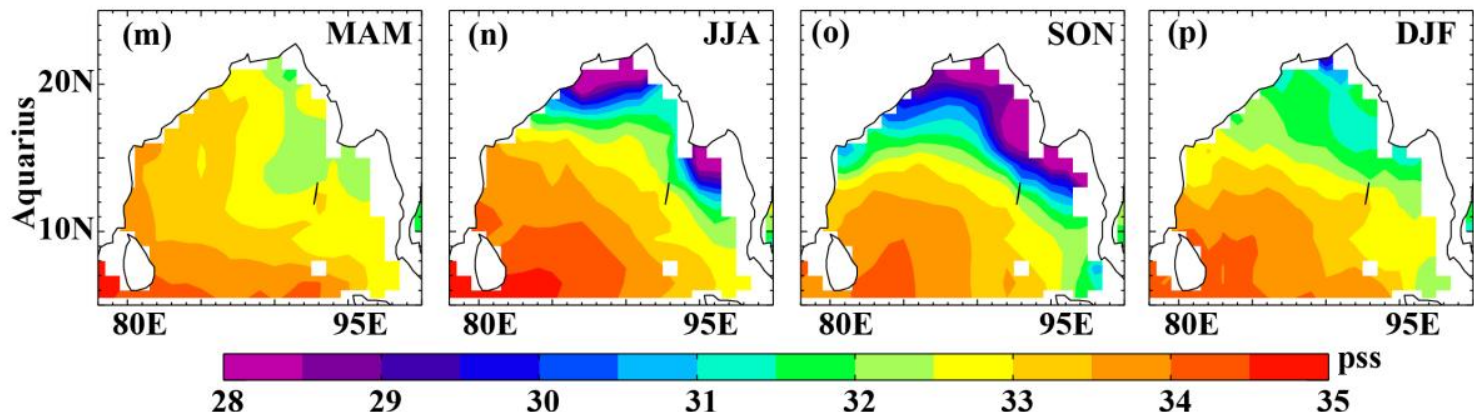

1032

Figure 9. Seasonal climatology of SSS in the BoB from (a-d) WOA18, (e-h) SMOSnew (January 2010-September 2019), (i-l) SMAP (April 2015-December 2019) and (mp) Aquarius (August 2011-June2015). 

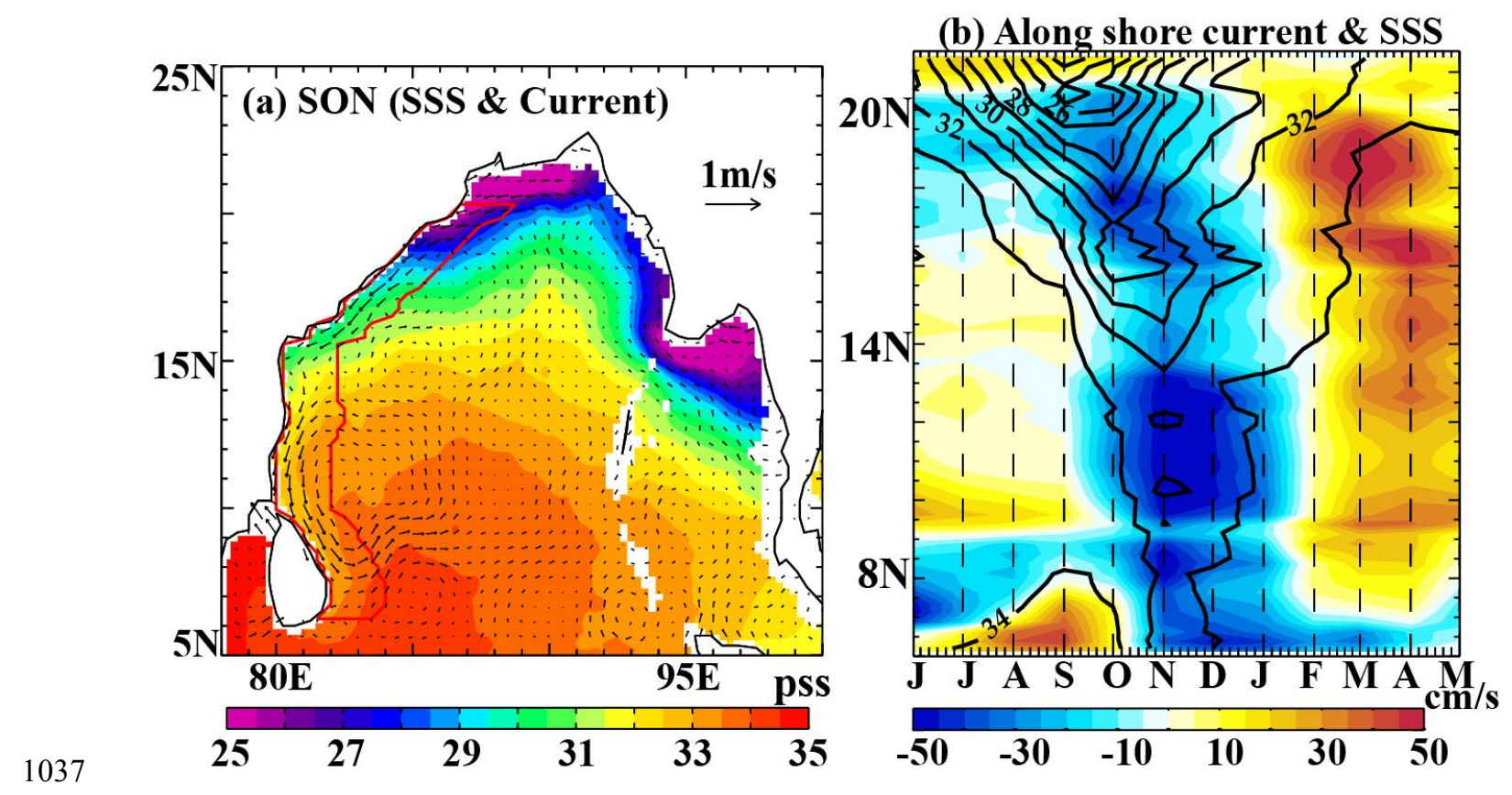

1038 Figure 10. (a) Climatological SON SMOS-new SSS (color) and SON GEKCO surface 1039 current (vectors). The red frame on panel (a) indicates the region used for the latitude1040 time section on panel (b). (b) Latitude-time section of the SMOS-new SSS (contours, 1041 pss) and GEKCO along-shore current (color, negative values indicate southward current) 1042 seasonal cycle in the coastal box defined in (a). 

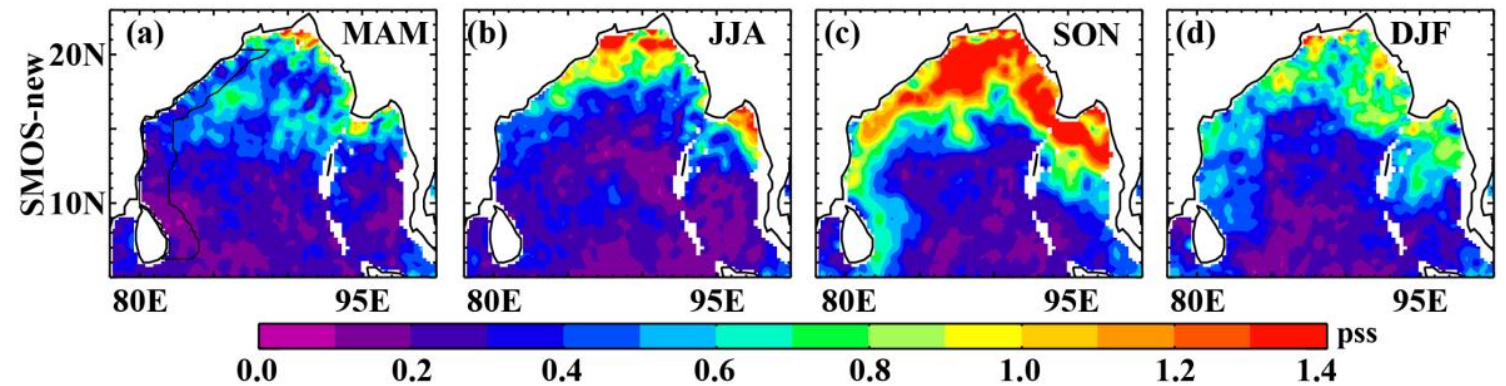

1045

Figure 11. Standard deviation of SMOS-new (January 2010-September 2019) SSS interannual anomalies for (a) MAM, (b) JJA, (c) SON and (d) DJF. The black frame on panel (a) indicates the box that is used for the latitude-time section in Figure 12. 

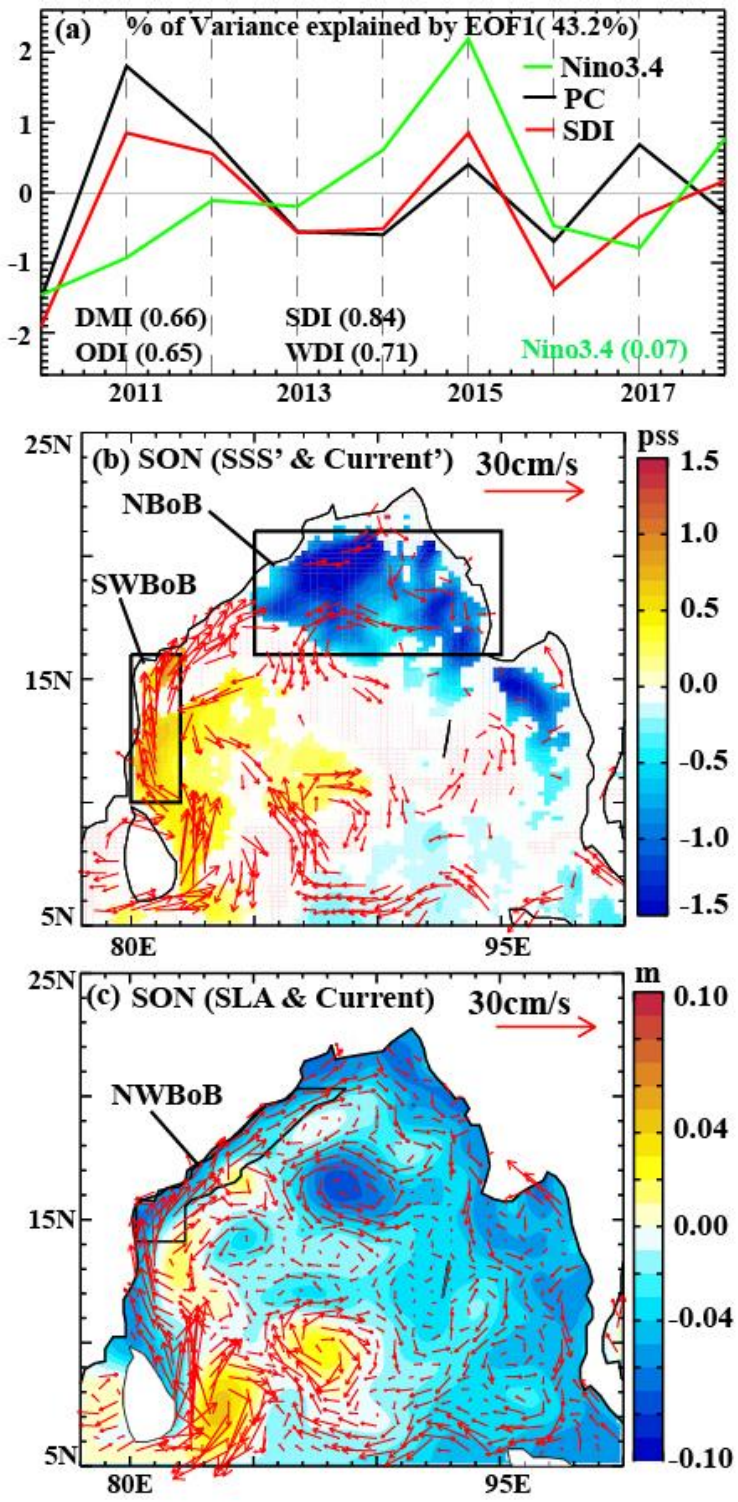

Figure 12. (a) Time series of the normalized principal component (PC1) of the first mode from an empirical orthogonal function (EOF) analysis of SON SMOS-new SSS interannual anomalies (black), normalized SON SLA-based Dipole Mode Index (SDI, red, see figure 3 and method section for definition) and ENSO index (Niño34, green) over the 2010-2018 period. The correlation of PC1 with the four different IOD indices and Nino3.4 index defined in the method section are indicated at the bottom of the panel. (b) Regression of SON SMOS-new SSS interannual anomalies (SSS', color) and GEKCO surface current interannual anomalies (Current', vectors) to PC1 over the 20102018 period. Signals that are not significantly different from zero at the $90 \%$ confidence level are masked. (c) Regression of SON AVISO SLA (shading), GEKCO surface current interannual anomalies (vectors) to SON SDI over the 2010-2018 period. The frames on panels (b) and (c) are used in Figure 14. 


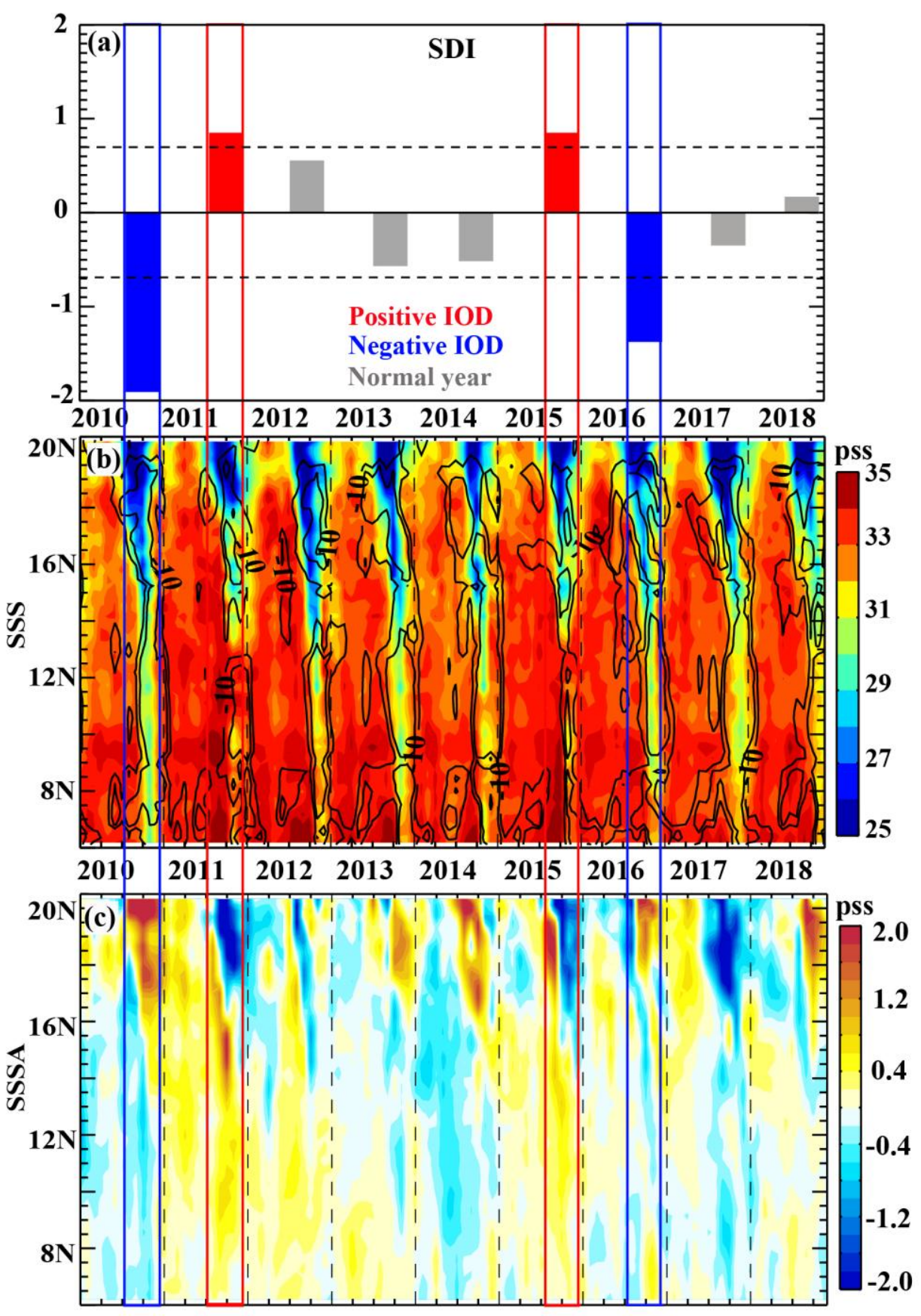

1063 Figure 13. (a) Bar diagram of average SON SLA-based dipole index (SDI) from 2010 to 2018. Latitude time section along the East Indian coast (boxes on Figure 10a and 11a) of monthly (b) SMOS-new SSS (colors, pss) and GEKCO along-shore current (Contour, $\mathrm{cm} / \mathrm{s}$; only southward currents are plotted as continuous contours every $\left.0.1 \mathrm{~m} . \mathrm{s}^{-1}\right),(\mathbf{c})$

1067 SMOS-new SSS interannual anomalies (colors, pss). The blue (red) frames delineate the 1068 September-November period of the two negative (positive) IOD years in 2010 and 2016 1069 (2011 and 2015). 

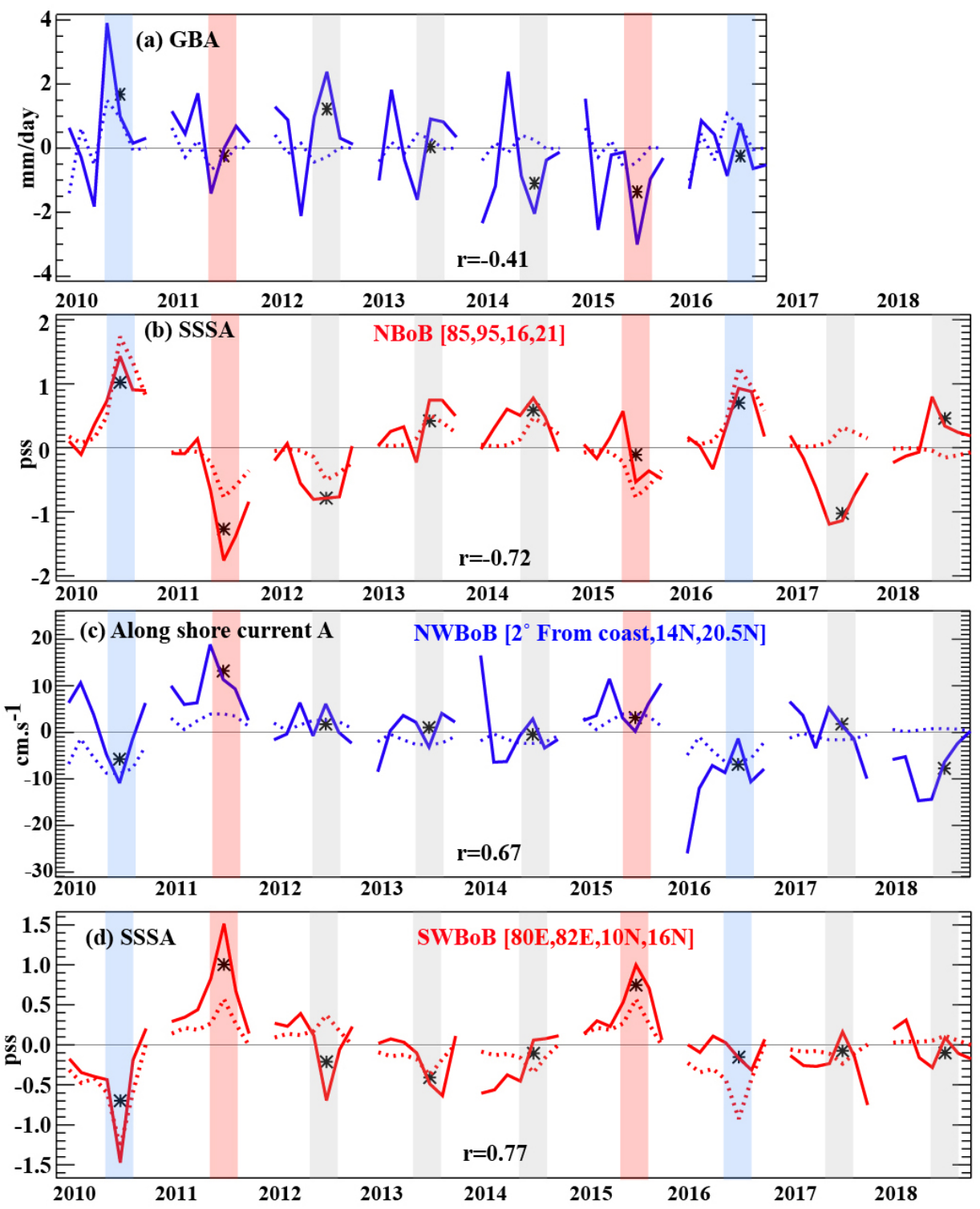

Figure 14: Time series of June to December for (a) Ganges-Brahmaputra River discharge anomaly (GBA, Blue; converted in mm.day ${ }^{-1}$ in NBoB oceanic area depicted on Figure 2b), (b) SSS anomaly in NBoB (red), (c) along-shore current anomaly (blue) in northwestern $\mathrm{BoB}\left(\mathrm{NWBoB}\right.$, i.e. $2^{\circ}$ from the coast along the east Indian coast; $14^{\circ} \mathrm{N}$ $20.5^{\circ} \mathrm{N}$; see frame on Figure $12 \mathrm{c}$ ), (d) SSS anomaly (red) in southwestern BoB $\left(\mathrm{SWBoB} ; 80^{\circ} \mathrm{E}-82^{\circ} \mathrm{E}-10^{\circ} \mathrm{N}-16^{\circ} \mathrm{N}\right.$; see frame on Figure $12 \mathrm{~b}$ ). Doted lines correspond to "typical" IOD signals, obtained by regressing interannual anomalies on the normalized SDI). Bars indicate the SON period (red for positive IOD years, blue for negative years and grey for normal years, derived from the SDI). Stars represent the mean SON values. The correlation (r) between the SON SDI and SON interannual anomalies of each variable is given on each panel. 

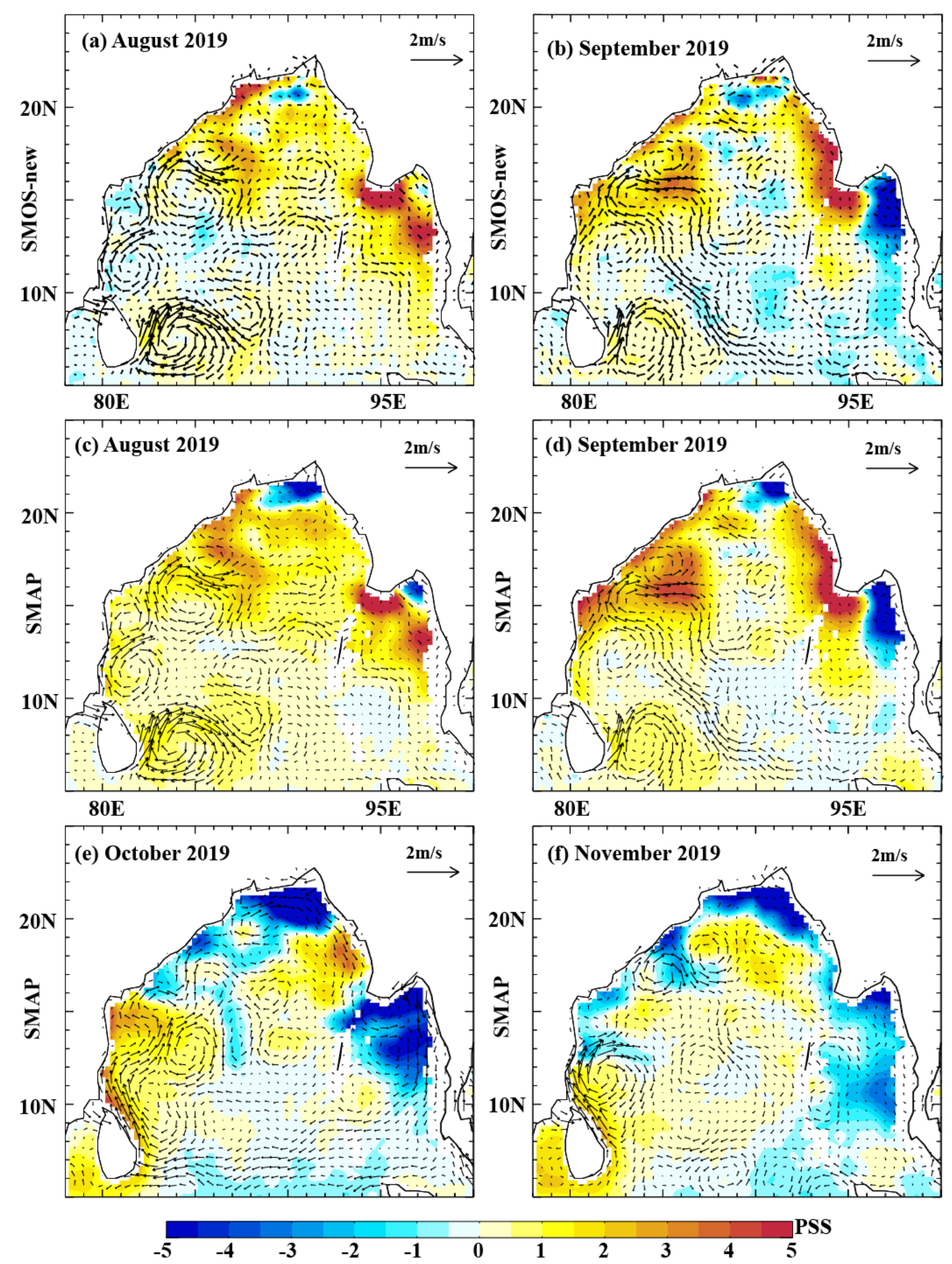

Figure 15: (a-b) August and September 2019 SMOS-new SSS anomalies (color) overlaid with GEKCO current anomaly (vector). (c-f) August to November 2019 SMAP SSS anomalies (color) overlaid with GEKCO current anomaly (vector). For this plot, the climatology is computed using the common June 2015 to May 2019 SMOS-new and SMAP period. 

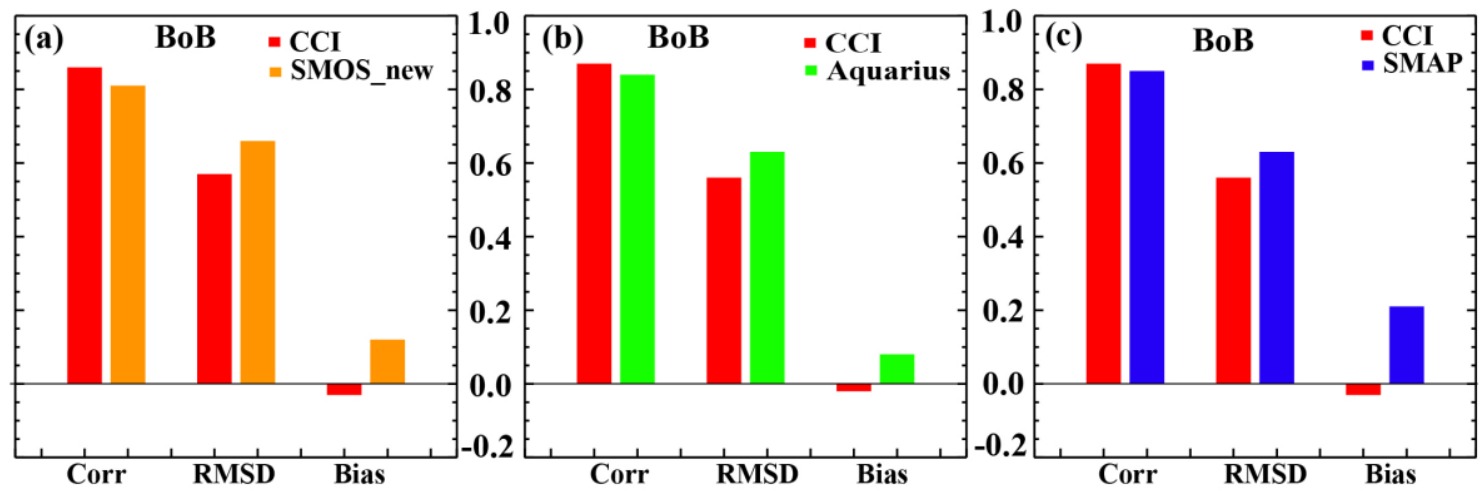

1090 Figure 16: Bar diagrams of comparisons between satellite products and co-located in 1091 situ SSS data over the entire BoB. The merged CCI-SSS product (2010 to October 2018) is compared with (a) SMOS-new, (b)

(b) Aquarius and

(c) SMAP over their common periods. The statistics on this figure are strictly comparable, since both satellite datasets on each panel are compared to the same common in situ data sample. 